\title{
1 Timely Schwann cell division during migration drives peripheral myelination in vivo via
}

\section{Laminin/cAMP pathway}

3 Keywords: sil; Schwann cells; peripheral nervous system; mitotic spindle; MCPH; zebrafish;

4 myelin; PLLn; mitosis; Laminin; cAMP.

$5 \quad$ Aya Mikdache ${ }^{1, \#, \lambda}$, Marie-José Boueid ${ }^{1, \lambda}$, Emilie Lesport ${ }^{1}$, Brigitte Delespierre ${ }^{1}$, Julien Loisel-

6 Duwattez ${ }^{1}$, Cindy Degerny ${ }^{1, *}$, Marcel Tawk ${ }^{1, *}$

$7 \quad *$ To whom correspondence should be addressed, e-mail: cindy.degerny@universite-paris-

$8 \quad$ saclay.fr; marcel.tawk@inserm.fr

$9 \quad{ }^{1}$ U1195, Inserm, University Paris-Saclay, 94276 Le Kremlin Bicêtre, France,

10 \# A Mikdache present address: UMR 3215 - U934, Institut Curie, 75005 Paris, France

$11 \lambda$ These authors contributed equally

\section{Summary}

14 Schwann cells (SC) migrate along peripheral axons and divide intensively to generate the

15 right number of cells prior to axonal ensheathment; however, little is known regarding the

16 temporal and molecular control of their division, particularly during migration, and its impact

17 on myelination. We report that Sil, a spindle pole protein associated with autosomal recessive

18 primary microcephaly $(\mathrm{MCPH})$, is required for temporal mitotic exit of SC. In sil-deficient

19 cassiopeia $\left(\mathrm{csp}^{-/}\right)$mutants, SC fail to radially sort and myelinate peripheral axons. Elevation

20 of cAMP, but not Rac1 activity in $c s p^{-/-}$restores myelin ensheathment. Most importantly, we

21 show a significant decrease in Laminin expression within $\operatorname{csp}^{-/}$posterior lateral line nerve and

22 that forcing Laminin2 expression in $\operatorname{csp}^{-/}$fully restores SC ability to myelinate. We also

23 discovered that SC have a restricted time window during which they have to divide, while

24 migrating, in order to trigger myelination. Thus, we unravel a novel and essential role for 
25 timely SC division during migration in mediating Laminin expression to orchestrate radial

26 sorting and peripheral myelination in vivo.

\section{Introduction}

29 Schwann cells are the myelinating glia that ensure efficient nerve impulse conduction along 30 the nerves of the peripheral nervous system (PNS) (Boucanova \& Chrast, 2020, Herbert \& 31 Monk, 2017, Jessen \& Mirsky, 2005, Pereira, Lebrun-Julien et al., 2012, Raphael, Lyons et 32 al., 2011, Sherman \& Brophy, 2005, Woodhoo \& Sommer, 2008). In order to myelinate, 33 Schwann cells go through a series of developmental changes that include i) migration and 34 division along peripheral axons ii) intensive proliferation prior to axonal ensheathment given 35 that one Schwann cell myelinates one axonal segment and iii) substantial cytoskeletal 36 rearrangements and changes in cell shape that allow a Schwann cell to radially sort an axon in 37 a 1:1 ratio, a process termed radial sorting (Feltri, Poitelon et al., 2016, Monk, Feltri et al., 38 2015, Raphael \& Talbot, 2011). The latter enables Schwann cells to extend their processes 39 along a specific and unique abaxonal-adaxonal polarity axis in order to select and sort an axon to myelinate (Tricaud, 2017). It has been shown that in vitro Schwann cells first secrete and 41 assemble their own basal lamina (BL) (Colognato \& Tzvetanova, 2011, Eldridge, Bunge et 42 al., 1989) that would later on regulate, through receptor interactions, different signals required 43 for Schwann cell proliferation, survival and differentiation (Chen \& Strickland, 2003, Court, 44 Hewitt et al., 2009, Nodari, Previtali et al., 2008, Nodari, Zambroni et al., 2007, Yamada, 45 Denzer et al., 1996, Yu, Feltri et al., 2005). Of particular interest are the extracellular matrix 46 (ECM) proteins Laminins and Collagens that play essential roles in Schwann cell 47 development (Chernousov, Yu et al., 2008). 
48 However, several issues regarding the characteristics of timely Schwann cell division during 49 migration and radial sorting, as well as the coupling of division with ECM proteins and $50 \quad$ myelination in vivo remain unresolved.

51 The mitotic spindle is a bipolar array of microtubules that mediates chromosome separation 52 during cell division (Hara \& Fukagawa, 2020, Petry, 2016). The organization and temporal 53 assembly of the spindle are all important features that dictate the outcome of division (Lu \& 54 Johnston, 2013). One critical aspect of cell division is the temporal control of mitosis; this is 55 highlighted by the existence of a mitotic spindle checkpoint that ensures accurate mitotic 56 spindle organization prior to anaphase. It generates a wait signal until mitotic checkpoint 57 proteins are removed from the kinetochore during metaphase by dynein/dynactin, clearing the way for accurate segregation of chromosomes into daughter cells (Lara-Gonzalez, Westhorpe et al., 2012). A great number of proteins is involved in spindle organization, one such major 60 player is Sil that is ubiquitously expressed and specifically localizes to the poles of the mitotic 61 spindle in metaphase cells (Campaner, Kaldis et al., 2005, Pfaff, Straub et al., 2007). The sil 62 gene was originally cloned from leukemia-associated chromosomal translocation and is 63 overexpressed in several tumor types such as melanoma and lung carcinomas (Aplan, 64 Lombardi et al., 1990, Aplan, Lombardi et al., 1991). It is associated with autosomal recessive 65 primary microcephaly $(\mathrm{MCPH})$, a neurogenic mitotic disorder that results in significantly 66 reduced brain size (Naveed, Kazmi et al., 2018, Zaqout, Morris-Rosendahl et al., 2017). 67 Studies of zebrafish cassiopeia mutant $\left(\operatorname{csp}^{-/-}\right)$, which has a nonsense mutation and a loss of 68 function in zebrafish sil, show abnormalities in prometaphase progression within retinal 69 neuroepithelium (Novorol, Burkhardt et al., 2013). Thus, sil represents an ideal candidate to 70 study for a role in mitotic synchronization and division during Schwann cells' development.

71 Here, we used live imaging, genetics and pharmacological tools in zebrafish to monitor 72 Schwann cell behavior during its division and unraveled for the first time an essential role for 
73 early Schwann division during migration in peripheral myelination. We identified Sil as a

74 critical regulator of Schwann cell radial sorting and myelination. Time-lapse imaging revealed

75 an important role for sil in Schwann cell metaphase progression that delayed mitotic exit and

76 caused a significant decrease of peripheral myelin markers, krox20 and $m b p$ in $c s p^{-/-}$embryos.

77 This coincided with a complete loss of axonal ensheathment as revealed by transmission 78 electron microscopy (TEM). Treating $c s p^{-/}$with forskolin that binds to adenyl cyclase and 79 elevates the levels of cAMP, restored radial sorting, myelin-associated genes expression and 80 axonal wrapping. Moreover, $\operatorname{csp}^{-/}$mutants failed to express Laminin within the posterior 81 lateral line nerve (PLLn) and forcing Laminin2 expression was sufficient to fully restore 82 peripheral myelination. These data unraveled an essential role for the timely process of 83 mitotic exit within Schwann cells, specifically during migration, in radial sorting and 84 myelination via Laminin2/cAMP dependent pathway. We provide evidence that Schwann 85 cells have a limited window of time in which they have to divide during their migration in 86 order to initiate radial sorting and myelination.

\section{Results}

Schwann cells show a regular pattern of division during radial sorting along the PLLn

90 In order to monitor Schwann cell division, we took advantage of the $T g(f o x d 3: g f p$ ) (Gilmour,

91 Maischein et al., 2002) and first imaged Schwann cells along the PLLn between 48 and 60

92 hours post-fertilization (hpf). During this time, Schwann cells divide intensively and start to

93 radially sort axons that precedes axonal ensheathment (Figure S1) (Lyons, Pogoda et al.,

94 2005, Raphael et al., 2011). Schwann cells were generally elongated along the axons until

95 they went through mitotic rounding that led to division and then re-elongated again (Figure

96 1A). Cells divided along the Anterior-Posterior (AP) axis of the embryo and it took an

97 average of $9.30 \pm 0.61 \mathrm{~min}$ for mitosis to complete (Figure $1 \mathrm{~B}$ and Movie S1). To assess the 
importance of this pattern of division in Schwann cell myelination, we decided to monitor their behavior in cassiopeia mutant $\left(c s p^{-/-}\right)$. Sil is a ubiquitously expressed protein that specifically localizes to the mitotic spindle in metaphase cells and plays a critical role in its organization (Novorol et al., 2013, Pfaff et al., 2007). Schwann cells' mitosis in $\operatorname{csp}^{-/}$took much longer to complete with an average of $90.10 \pm 14.13 \mathrm{~min}$ in comparison to $9.30 \pm 0.61$ min in controls (Figure 1A,B and Movie S2). However, re-elongation of Schwann cells occurred normally after division in both mutants and controls (Figure 1A).

This result suggests that Sil deficiency leads to a significant delay in Schwann cell mitosis.

\section{Sil is essential for Schwann cell radial sorting and myelination}

Having identified a delay in progression through mitosis in $c s p^{-/-}$Schwann cells, we wondered whether this defect could have any impact on the ability of Schwann cells to ensheath axons. Transmitted Electron Microscopy (TEM) analysis showed a dramatic decrease in the number of myelinated axons in $c s p^{-/}$in comparison to controls. We observed an average of $5.6 \pm 0.55$ myelinated axons per nerve in controls in comparison to 0 myelinated axon per nerve in $\operatorname{csp} p^{-/}$ at $72 \mathrm{hpf}$ (or 3 days post-fertilization (dpf)) (Figure 2A,B,E). In addition, we observed a significant decrease in the total number of axons in these mutants with an average of $55 \pm 2.85$ axons in controls and 28.63 \pm 2.67 in $c s p^{-/}$PLLn (Figure 2F). In order to test whether this defect is maintained at later stages, we analyzed axonal wrapping at $4 \mathrm{dpf}$. The myelination defect in $\operatorname{csp}^{-/}$embryos detected at $3 \mathrm{dpf}$ was also observed at $4 \mathrm{dpf}$ (Figure 2C-F). This analysis could not be extended to later stages since $c s p^{-/}$embryos died between 4 and $5 \mathrm{dpf}$.

Given the drastic decrease in total number of axons in these mutants, we therefore calculated the ratio of myelinated axons relative to the total number of axons in the PLLn. While we counted an average of $10.46 \pm 1.14 \%$ of myelinated axons in controls, we observed $0 \%$ in $c s p^{-/-}$ at 3 and $4 \mathrm{dpf}$ (Figure 2G). This myelination defect was not the result of a decrease in the 
123 number of large caliber axons that are supposed to be myelinated (Figure $2 \mathrm{H}$ ). Finally, the

124 myelination defect coincided with a significant decrease in the number and the percentage of 125 radially sorted axons per nerve (Figure 2I,J).

126 These results show that sil is required for Schwann cell radial sorting and myelination.

128 Sil is required within Schwann cells for axonal wrapping and normal Mbp expression 129 and regulates the number of neurons within the PLLg

130 Sil is ubiquitously expressed but highly enriched in neural cells and $c s p^{-/}$embryos show 131 major neuronal defects such as an increase in the percentage of mitotically arrested 132 neuroepithelial cells in the retina that coincides with an increase in apoptosis (Novorol et al., 133 2013). To test whether the myelination defect observed here is specific to Schwann cell or 134 secondary to neuronal defects, we first examined several aspects of posterior lateral line 135 ganglia (PLLg) and PLLn development in these mutants. Csp $^{-/-}$embryos presented no major 136 defects in PLLn growth and Schwann cell migration at 48 hpf along the PLLn (Figure S2A).

137 A few $c s p^{-/-}$embryos $(<30 \%, \mathrm{n}=7 / 24)$ showed an axonal growth arrest but posterior to the 138 yolk extension and Schwann cells were found at the tip end of these axons. We next analyzed 139 axonal transport along the PLLn using mito:gfp construct that labels mitochondria and we 140 monitored their behavior by time-lapse imaging. We observed no significant difference in the 141 average speed of mitochondria along the PLLn with an average of $1.92 \pm 0.14 \mu \mathrm{m} / \mathrm{s}$ and $1421.85 \pm 0.06 \mu \mathrm{m} / \mathrm{s}$ in controls and $c s p^{-/-}$respectively (Figure S2B,C and Movies S3, S4). We 143 next looked at the PLLg and counted the number of neurons within the ganglia using the 144 neuronal marker HuC. We observed a significant decrease in the number of neurons in $c s p^{-1-}$ 145 embryos at 48 and $72 \mathrm{hpf}$ in comparison to controls (Figure S2D,E) suggesting a role for sil in 146 the development of PLLg that coincides with the reduction in the number of axons in the 147 PLLn. 
148 These results suggest a role for sil in the development of PLLg but not in axonal growth or 149 transport.

150 To directly test whether sil has an autonomous function in Schwann cell myelination, we 151 forced the expression of sil specifically in Schwann cells under the control of the sox10 152 promoter. $C s p^{-/}$embryos were injected with pTol2-sox10:sil-P2A-mcherry-CaaX and tol2 153 transposase mRNA at 1 cell stage and selected at 3 dpf for mcherry expression in Schwann 154 cells to be later fixed for TEM analysis. By forcing the expression of sil specifically in

155 Schwann cells, we significantly increased the number of myelinated axons in $\operatorname{csp} p^{-/-}$embryos at 1563 dpf (Figure 3A-B"'). The percentage of myelinated axons per nerve in $c s p^{-/}$injected 157 embryos was similar to the one observed in controls (Figure 3C).

158 We also processed control and $c s p^{-/-}$larvae for immunohistochemistry to detect Mbp at 3 dpf.

159 We observed a sharp decrease in Mbp expression in $c s p^{-/}$embryos in comparison to controls

160 (Figure 3D-E'). We then injected $c s p^{-/-}$embryos with pTol2-sox10:sil-P2A-mcherry-CaaX 161 and tol2 transposase mRNA at 1 cell stage and selected embryos for mosaic mcherry+ clonal 162 analysis. These embryos were then processed for immunohistochemistry to detect Mbp. We 163 analyzed 4 mutant larvae that had sox10:mcherry ${ }^{+}$Schwann cells along mutant PLLn; the 164 mcherry+ clones appeared to express normal levels of Mbp (Figure 3F-G'’).

165 Altogether, these results suggest a specific requirement for sil within Schwann cells to initiate 166 axonal wrapping and Mbp expression.

167

168 Schwann cells in $\operatorname{csp}^{-/-}$show delays in mitotic progression but exit mitosis with no 169 significant increase in apoptosis

170 Given that sil deficiency leads to a decrease in the number of neurons with significant 171 apoptosis in the retina, it is possible that the myelination defects observed in the PLLn of $c s p$

172 - embryos could be related to a defect in the number of Schwann cells and/or their survival. 
173 To address this question, we first labeled Schwann cells using the M phase marker PH3 in

$174 \operatorname{Tg}($ foxd3:gfp) at 48 and 72 hpf. As seen in the retina (Novorol et al., 2013), we observed a

175 significant increase in the fraction of proliferating PH3+/Schwann cells at $48 \mathrm{hpf}$. This

176 coincided with a decrease in the total number of Schwann cells and an increase in the ratio of

177 PH3 + Schwann cells relative to the total number of Schwann cells counted within a region of

1788 somites (Figure 4A-D). However, results were different at $72 \mathrm{hpf}$, as the total number of

179 Schwann cells, the number of PH3+/Schwann cells and the ratio of PH3+/Schwann cells

180 relative to the total number of Schwann cells showed no significant difference between

181 controls and $c s p^{-/}$embryos (Figure 4A-D). Moreover, time-lapse analysis using the nuclear

182 marker $h 2 b: g f p$ pointed to a delay in prometaphase progression (Figure 4E and Movies S5,

183 S6). However, in contrast to the neuronal phenotype in retina, most of Schwann cells exited

184 mitosis and we detected no apoptotic Schwann cells in these mutants along the PLLn (Figure

185 4F,G). We also observed a significant increase in the number of acridine orange (AO)+ cells

186 within the spinal cord that is comparable to the defect observed in the zebrafish retina

187 suggesting a role for sil in cell survival outside the brain (Figure 4F,H).

188 These data suggest that sil is required in Schwann cells for the temporal control of mitotic

189 exit, nevertheless, Schwann cells devoid of sil do exit mitosis following a significant delay

190 and are not apoptotic.

192 Cell division during radial sorting is not required per se for Schwann cell myelination

193 Since Schwann cells in $c s p^{-/-}$embryos show a delay in their mitotic progression, it is possible

194 that there is a window of time during radial sorting in which Schwann cell have to divide in

195 order to myelinate. Moreover, it has been shown that blocking cell division during radial

196 sorting can alter their ability to radially sort axons and myelinate (Raphael et al., 2011). To

197 test this hypothesis, we treated embryos with aphidicolin that blocks cell division in vivo in 
198 zebrafish (Lyons et al., 2005, Raphael et al., 2011). First, we incubated embryos in

199 aphidicolin between 45 and 54 hpf (see Materials and Methods for aphidicolin 200 treatment/efficacy) to temporarily inhibit cell division during the initial phase of radial

201 sorting. The medium was then washed and embryos were allowed to develop until $72 \mathrm{hpf}$ (or

$2023 \mathrm{dpf}$ ) to be fixed for TEM. Another group of embryos was incubated from $45 \mathrm{hpf}$ until $72 \mathrm{hpf}$

203 to block Schwann cell division during the whole period of radial sorting. TEM analysis

204 showed a significant decrease in the number of myelinated axons in both groups of treated 205 embryos but also, as expected, in the total number of axons within the PLLn (Figure 5A-E).

206 However, some large caliber axons were myelinated. Most importantly, the ratios of

207 myelinated axons as well as the ratios of axons per diameter relative to the total number of

208 axons showed no significant difference between the different groups (Figure 5F-H).

209 This result suggests that cell division during radial sorting is not required per se for peripheral 210 myelination.

\section{Sil is required for mitotic temporal exit during Schwann cell migration}

213 Given that cell division during radial sorting is not required per se for Schwann cell

214 myelination, we therefore tested whether sil is also implicated in early Schwann cell division

215 during migration. For this, we monitored Schwann cell behavior during axonal growth when

216 Schwann cells migrate and divide along the axons of the PLLn. Schwann cells were generally

217 elongated during migration too until they went through mitotic rounding, divided and then re-

218 elongated (Figure 6A, Movie S7). Schwann cells divided along the AP axis of the embryo and

219 it took an average of $9.81 \pm 0.63 \mathrm{~min}$ for them to complete mitosis, showing a very similar

220 behavior to the one observed during radial sorting. However, Schwann cells struggled to exit

221 mitosis in $\operatorname{csp}^{-/}$with an average of $87.20 \pm 4,72 \mathrm{~min}$ for mitosis to be completed (Figure 6A,B,

222 Movie S8). 
223 This result shows that sil is also required for the temporal control of mitosis in Schwann cell

224 during migration similar to what we observed during radial sorting.

225

226 Early Schwann cell division during migration is essential for peripheral myelination

227 Since sil is also required for the temporal control of Schwann cell mitosis during migration, it

228 is possible that the myelination defects observed in $\operatorname{csp} p^{-/}$result from a defective division

229 during these earlier events. It has been shown that Schwann cell division during migration is

230 not required for migration per se (Lyons et al., 2005), however whether it is required for

231 myelination has not been tested yet. We therefore treated embryos with aphidicolin to block

232 cell division specifically during Schwann cell migration (between 22 and $40 \mathrm{hpf}$ ) and before

233 radial sorting. The medium was then washed and embryos were allowed to develop until 3

$234 \mathrm{dpf}$ to be fixed for TEM. As expected, there was a sharp decrease in the total number of axons

235 per nerve, however, we counted an average of only 0.125 myelinated axon in aphidicolin

236 treated embryos at $3 \mathrm{dpf}$ (Figure 7A-E). To test whether Schwann cells were able to divide

237 again during radial sorting once the medium is washed, we analyzed their division and

238 numbers during radial sorting, here at 52 hpf. We observed a significant decrease in the

239 number of Schwann cells in treated embryos at $52 \mathrm{hpf}$ but the number of Schwann cells that

240 are $\mathrm{PH} 3+$ and the ratio of $\mathrm{PH} 3+$ Schwann cells relative to the total number of Schwann cells

241 were similar between controls and treated embryos (Figure 7F-H). This result shows that

242 Schwann cells were able to divide again during radial sorting following the temporal cell

243 division block during migration.

244 We also monitored Schwann cell division during radial sorting using live imaging in controls

245 and treated embryos. Our results showed a normal pattern of division during radial sorting in

246 treated embryos similar to controls (Figure 7I,J, Movies S9,10). 
247 Altogether, these results point to an essential role for Schwann cell division during migration 248 in myelination.

Sil is required to initiate radial sorting, myelin gene expression and axonal wrapping by

\section{Schwann cells via cAMP pathway}

252 M phase is characterized by chromatin condensation and temporal ejection of transcription

253 factors (Ma, Kanakousaki et al., 2015). Since sil is implicated in spindle checkpoint and

254 mitotic progression during $M$ phase, it is possible that the delayed mitotic exit observed in

$255 \operatorname{csp}^{-/}$embryos could result in prolonged ejection of transcription factors required for

256 myelination in Schwann cells. Alternatively, it is possible that transcriptional activity is

257 effective after mitosis but Schwann cells in $\operatorname{csp} p^{-/}$embryos present defective upstream

258 signaling activity. To distinguish between these possibilities, we first analyzed the expression

259 of $k$ rox 20 and $m b p$ in controls and $c s p^{-/-}$embryos at $52 \mathrm{hpf}$ and $3 \mathrm{dpf}$ respectively. $c s p^{-/-}$

260 embryos showed a sharp decrease in the expression of peripheral myelin genes (Figure 8B,E)

261 in comparison to controls (Figure 8A,D) confirming the role of sil in this process. This

262 coincided, as shown before, with a total lack of radial sorting and axonal ensheathment

263 (Figure 8H). Second, we decided to treat embryos with forskolin that interacts with adenyl

264 cyclase and elevates the levels of cAMP. It has been shown that elevation of cAMP in vivo in

265 zebrafish is able to re-initiate the defective expression of myelin transcription factors in

266 gpr126 mutant (Monk, Naylor et al., 2009). Indeed, when $\operatorname{csp}^{-/}$embryos were treated with

267 forskolin during radial sorting, the expression of krox20 and $m b p$ was restored (Figure 8C,F)

268 as well as the ratio of myelinated axons relative to the total number of axons (Figure 8I,J).

269 This result suggests that the myelin defects observed in $c s p^{-/-}$embryos result from a defective

270 cAMP signaling pathway and not from a prolonged ejection of transcription factors following

271 a particularly lengthy M phase. 


\section{Forcing Rac1 activity does not rescue radial sorting and myelination defects in $c s p^{-/-}$}

274 The radial sorting defect and lack of axonal ensheathment by Schwann cell observed in this

275 mutant might also be linked to a defective cytoskeletal re-arrangement mediated by Rac1. To

276 test this hypothesis, we forced the expression of Rac1, a small GTPase protein that interacts

277 with Schwann cell cytoskeleton (Nodari et al., 2007) and is able to restore peripheral radial

278 sorting defects in zebrafish (Boueid, Mikdache et al., 2020, Mikdache, Fontenas et al., 2020).

$279 \operatorname{csp}^{-/}$embryos injected with a constitutive active form of Rac1 were comparable to non-

280 injected $c s p^{-/}$embryos and showed a total lack of radial sorting and axonal ensheathment

281 (Figure 8K,L).

282 This result suggests that $\operatorname{csp}^{-/-}$myelin defects do not ensue from a defective Rac1 activity.

\section{Forcing Laminin $\alpha 2$ expression fully rescues myelination defects in $\operatorname{csp}^{-/-}$}

285 Previous studies have shown that Laminin211 promotes myelination via GPR126/cAMP

286 dependent pathway (Petersen, Luo et al., 2015), and since forskolin treatment of $\operatorname{csp}^{-/-}$

287 embryos is sufficient to re-establish myelination in these mutants, we hypothesized that

288 Laminin 211 expression and/or function might be impaired in these mutants. To test this, we

289 first analyzed Laminin expression at $48 \mathrm{hpf}$ in controls and $c s p^{-/}$embryos using

290 immunostaining. Indeed, Laminin expression was significantly reduced along the PLLn of

$291 \mathrm{csp}^{-/}$embryos in comparison to controls (Figure 9A-C). We next wondered whether

292 increasing extracellular Lama2 levels would rescue the myelination defect observed in $\operatorname{csp}^{-/}$.

293 To this end, we took advantage of a lama2 overexpression construct that expresses membrane

294 EGFP as well as secreted mCherry-tagged Lama2 under the control of muscle-specific

295 skeletal-alpha actin (actal) promoter (Sztal, Sonntag et al., 2012) (Petersen et al., 2015) and

296 injected $20 \mathrm{pg}$ of this construct into $c s p^{-/-}$mutants. A wide and important amount of Laminin 
297 is secreted from muscle cells within the vicinity of PLLn in this case. Embryos that showed

298 significant expression of EFGP within PLLn surrounding muscles and mCherry-tagged within

299 PLLn (Figure 9D,E) were then selected and analyzed by TEM at 3 dpf. $c s p^{-/}$injected embryos

300 showed a significant increase in the number of myelinated axons in comparison to non-

301 injected $c s p^{-/-}$larvae and were comparable to controls (WT lama2 injected embryos) for the

302 percentage of myelinated axons relative to the total number of axons (Figure 9F-J).

303 These results strongly suggest a defective Laminin expression and function within the PLLn

304 of $c s p^{-/-}$mutant that is responsible for its radial sorting and myelination defect.

305 Laminin2 is known to control several aspects of Schwann cell development such as 306 proliferation and differentiation (Chernousov et al., 2008). We therefore wondered whether

307 Lama2 overexpression impacts on Schwann cell timely division and/or proliferation to

308 mediate myelination or it just triggers the radial sorting/myelination process regardless of the

309 number of Schwann cells. Indeed, Schwann cells numbers at $48 \mathrm{hpf}$ were comparable

310 between $c s p^{-/-}$and $c s p^{-/-}$-pactal-lama2 injected embryos and showed a delay in mitotic exit

311 similar to the one observed in $\operatorname{csp}^{-/}$embryos during migration and prior to axonal

312 ensheathment (Figure 9K-M). This result strongly suggests that the myelination defect

313 observed in $\operatorname{csp}^{-/}$is due to defective Laminin/cAMP pathway and that the temporal reduction

314 in Schwann cells' numbers is not essential for myelination to proceed.

316 Schwann cells have a limited window of time to divide during migration in order to

\section{7 trigger myelination}

318 Our findings have revealed an essential role for the temporal control of Schwann cell division 319 during migration, mediated by Sil, in promoting radial sorting and myelination in vivo via 320 Laminin2/cAMP pathway. This led us to hypothesize that Schwann cells might have a limited

321 window of time during which they have to divide while migrating in order to trigger radial 
322 sorting and myelination once migration is completed. First, we tested whether blocking cell

323 division during migration would alter Laminin expression within the PLLn as observed in sil

324 mutants. Embryos incubated in aphidicolin during Schwann cell migration showed a

325 significant decrease in the expression of Laminin along the PLLn at $48 \mathrm{hpf}$ (Figure 10A-C).

326 Second, we treated embryos with aphidicolin for different periods of time during migration

327 and our results showed that Schwann cells have a limited time window of around $8 \mathrm{~h}$ in which

328 they have to divide in order to myelinate (Figure 10F and S3; see Materials and Methods for

329 aphidicolin treatment/efficacy). To test if this temporal delay in division that results in radial

330 sorting and myelination defects is related to a defective Laminin expression/function, we

331 injected embryos with 20 pg of lama2 overexpression construct and treated embryos with

332 aphidicolin between 22 and $30 \mathrm{hpf}$. The group of lama 2 injected embryos and treated with

333 aphidicolin showed a significant increase in the number of myelinated axons in comparison to

334 treated non-injected embryos (Figure 10D-H) and the percentage of myelinated axons relative

335 to the total number of axons was similar to controls (Figure 10I).

336 This result strongly suggests a restricted time window for Schwann cells to divide while

337 migrating during which Laminin expression is triggered.

338

339 Schwann cells are a major source of Laminin within the PLL nerve and forcing

340 Laminin $\alpha 2$ expression within Schwann cells rescues Mbp expression in $\operatorname{csp}^{-/-}$and

341 aphidicolin treated embryos

342 Results so far have shown a strong correlation between timely Schwann cell division during

343 migration, Laminin expression and subsequent myelination. However, it remained important

344 to determine the source of Laminin within the PLLn and whether Schwann cell specific

345 expression of Laminin would rescue myelination autonomously in sil mutant and aphidicolin

346 treated embryos. To do so, we first incubated embryos with AG1478 that specifically blocks 
347 ErbB signaling in zebrafish and inhibits Schwann cell migration along the PLLn (Lyons et al.,

348 2005). Embryos treated with AG1478 between 24 and 48 hpf presented no Schwann cells

349 along the PLLn and showed a significant decrease in Laminin expression at 48 hpf (Figure

$350 \quad 11 \mathrm{~A}-\mathrm{C})$.

351 This result establishes Schwann cells as a major source of Laminin within the PLLn.

352 Second, we designed a pUAS-lama2-EGFP-mcherry construct and took advantage of the $353 \operatorname{tg}(\operatorname{sox} 10:$ Gal4VP16) to allow a specific expression of Lama2 within Schwann cells (EGFP+ 354 labeling); Lama2 is also found secreted within the PLLn (mCherry+ labeling) (Figure 11D355 E','). We injected $20 \mathrm{pg}$ of plasmid in sox10:Gal4VP16 and $\operatorname{csp}^{-1 /} /$ sox10:Gal4VP16 at one 356 cell stage and proceeded for EGFP and Mbp immunostaining for clonal analysis at 3 dpf. 357 Injected $c s p^{-/-}$embryos that showed an expression of EGFP in Schwann cells along the PLLn 358 expressed normal levels of Mbp while those that were negative to EGFP labeling showed a 359 significant decrease in Mbp expression similar to non-injected $c s p^{-/}$larvae (Figure 11F-H').

360 Moreover, we injected pUAS-lama2-EGFP-mcherry construct in sox10:Gal4VP16 and 361 incubated embryos in aphidicolin during Schwann cell migration (22-34 hpf). Aphidicolin 362 treated embryos that showed an expression of EGFP in Schwann cells along the PLLn 363 expressed normal levels of Mbp while those that were negative to EGFP labeling showed a 364 significant decrease in Mbp expression at 3 dpf (Figure 11I-J'”).

365 These results strongly suggest that Schwann cell division during migration is largely 366 responsible of early Laminin expression within the PLLn. This constitutes a crucial step for 367 timely myelination.

\section{Discussion}

370 Schwann cells migrate and divide along peripheral axons and the intimate contact between the 371 two contributes to Schwann cell proliferation, mainly through the neuregulin/ErbB axis. Other 
372 signals provided by ECM proteins that Schwann cells secrete, are also important for their

373 proliferation (Bunge, Clark et al., 1990, Bunge, Williams et al., 1982, Lyons et al., 2005,

374 Michailov, Sereda et al., 2004, Nave \& Salzer, 2006). Here, we investigate the characteristics

375 of Schwann cell division during migration and radial sorting and their impact on myelination.

376 We show that the temporal control of mitotic exit within Schwann cells is tightly controlled

377 by the spindle pole protein Sil. We provide evidence that timely division of Schwann cells

378 during migration is essential for radial sorting and myelination.

379 Schwann cells must regulate their numbers in order to myelinate or ensheath all axons that are

380 supposed to be myelinated by the end of radial sorting (Jessen \& Mirsky, 2005), so one would

381 predict that reducing the number of Schwann cells in the nerve would result in a reduction of

382 myelinated axons. Indeed, several molecules that control Schwann cell proliferation have

383 been identified such as $\mathrm{Cdc} 42$, focal adhesion kinase and several extracellular matrix proteins

384 of the laminin family such as laminin-2, 8 and $\gamma 1$ (Benninger, Thurnherr et al., 2007, Grove,

385 Komiyama et al., 2007, Yang, Bierman et al., 2005). Specific ablation of these molecules in

386 Schwann cells causes a reduction in the number of myelinated axons.

387 However, how important is the timely division of Schwann cells? If Schwann cells divide

388 intensively during radial sorting to generate the right numbers prior to axonal ensheathment,

389 then how would early division during migration contribute to myelination? Are insufficient

390 Schwann cell numbers per se a cause for radial sorting and myelination defects? The

391 importance of Schwann cell division during radial sorting has been examined in vivo (Raphael

392 et al., 2011), showing that blockade of cell division leads to significant defects in radial

393 sorting and myelination by Schwann cells. Several parameters should be considered in order

394 to assess the role of division in myelination following aphidicolin treatment, that is obviously

395 the drastic decrease in the total number of axons in the PLLn and the reduction in the number

396 of Schwann cells. Our results show that Schwann cell division during radial sorting is not 
397 required for myelination per se since blocking cell division reduces the number of myelinated

398 axons in the PLLn but not the ratio of myelinated axons relative to the total number of axons

399 resulting from this treatment. While aphidicolin-treated embryos during radial sorting show a

400 normal percentage of myelinated axons, $c s p^{-/-}$ones are totally devoid of radial sorting and

401 myelination. However, when analyzing earlier events, we discovered that early Schwann cell

402 division during migration, as well as the temporal control of its mitotic exit are essential in

403 this process. These findings demonstrate that Schwann cells have a restricted time window

404 during which they have to divide, specifically while migrating, in order to set up and initiate

405 myelin wrapping at later stages.

406 How might Sil control radial sorting and myelination in the PNS?

407 Since $c s p^{-/-}$embryos show a radial sorting defect, it remains possible that the myelination

408 defects result, at least partially, from a defective cytoskeletal re-arrangement mediated by

409 Rac1. Indeed, Schwann cells require a drastic process extension of their membrane in order to

410 sort individual axons from within a bundle. A group of genes that regulate this aspect of

411 Schwann cell behavior has been identified and includes elmol, dockl, $\beta 1$ integrin and ILK

412 (Cunningham, Herbert et al., 2018, Feltri, Graus Porta et al., 2002, Mikdache et al., 2020).

413 Some evidence points towards a role for these molecules in activating the small GTPase Rac1

414 that acts upon Schwann cells cytoskeleton during radial sorting (Guo, Moon et al., 2012,

415 Nodari et al., 2007). Our analysis strongly suggests that the myelination defects observed in

$416 c s p^{-/-}$do not result from a defective Rac1 activity since forcing the expression of Rac1 does

417 not rescue, even partially, this defect.

418 Schwann cells in $\operatorname{csp}^{-/-}$struggle to progress through the M phase of the cell cycle and show a 419 severe reduction in the expression of krox20. This phase is characterized by chromatin 420 condensation and by ejection of transcription factors and chromatin binding proteins (Ma et 421 al., 2015). Schwann cells are no exception since major chromatin remodeling complexes are 
422 present and play an important role in temporal Schwann cell development (Frob \& Wegner, 423 2019, Gomis-Coloma, Velasco-Aviles et al., 2018). It is possible that Schwann cell 424 transcription factors required for the initiation of myelination are permanently ejected in $c s p^{-1-}$ 425 following the temporal defect in M phase progression and therefore unable to bind the DNA. 426 Another possibility is a defective upstream signaling activity in $c s p^{-/}$embryos that blocks 427 Schwann cell differentiation, assuming that chromatin accessibility is re-established after 428 division. Our analysis suggests that it is rather a defective signaling activity that is responsible 429 for the peripheral lack of myelin observed in $c s p^{-/-}$embryos and that transcription activity is 430 responsive to upstream signaling cues.

431 Two major signaling pathways are required for several aspects of Schwann cell development, 432 that are the Neuregulin/ErbB and the Gpr126/cAMP signaling pathways (Monk et al., 2009, 433 Newbern \& Birchmeier, 2010). The neuregulin/ErbB plays a major role in migration, 434 survival, proliferation, radial sorting and myelination by Schwann cells through a plethora of 435 downstream factors such as PI3K/Akt, MEK/ERK and Cdc42 (Glenn \& Talbot, 2013, 436 Newbern \& Birchmeier, 2010). The Gpr126 pathway signals through cAMP and activates 437 myelination by elevating the levels of cAMP so that a forskolin treatment of gpr126 mutants 438 fully restores myelin ensheathment (Monk et al., 2009). However, elevating cAMP in 439 zebrafish erbb2 mutants does not rescue its myelin defects (Glenn \& Talbot, 2013). A 440 forskolin treatment of $c s p^{-/-}$embryos fully rescues radial sorting defects, restores krox20 and $441 m b p$ expression as well as axonal ensheathment, suggesting a defective cAMP pathway 442 activity in these mutants.

443 A particularly interesting observation is the difference in sil deficiency phenotype between 444 retina and Schwann cells. Sil is a ubiquitously expressed protein and is involved in the 445 fundamental process of mitosis but is highly enriched in the nervous system. Neurons might 446 in this case be more sensitive to Sil defects leading to massive apoptosis within the central 
447 nervous system (CNS); however, it is Schwann cell differentiation that is impaired in $c s p^{-/-}$

448 with no increase in apoptosis. It is therefore possible that different cells might respond

449 differently to sil defects and our results suggest that MCPH genes have a broader requirement

450 during development that is not solely confined to neuronal cells in the CNS. It is also

451 important to note that zebrafish dynein cytoplasmic 1 heavy chain 1 (dynclhl) mutant shows

452 comparable myelin defects to $c s p^{-/-}$(Langworthy \& Appel, 2012). Dynein is involved in

453 spindle organization and checkpoint (Grava, Schaerer et al., 2006, Kiyomitsu \& Cheeseman,

454 2012, Silva, Reis et al., 2014) similar to Sil and therefore it is highly possible that spindle

455 checkpoints proteins are fundamentally required for the temporal control of mitosis within

456 Schwann cells in order to initiate myelination.

457 One important question remained to be solved: what is the molecular link between Schwann 458 cell division, its temporal control and cAMP pathway? Our analyses have shown an essential 459 role for Sil in Schwann cell differentiation, this added to the fact that cAMP stimulation 460 rescued the myelination defects prompted us to test for upstream signals that mediates cAMP 461 activity. Several studies have now established an essential role for the Gpr126 in driving 462 cAMP activity in Schwann cells through G proteins (Mogha, Benesh et al., 2013) and this has 463 recently been attributed to Gpr126 interaction with ECM, more specifically with Laminin211 464 (Petersen et al., 2015). It is therefore possible that sil deficient Schwann cells are incapable of 465 secreting extracellular proteins and/or responding to them to drive the ECM/Gpr126/cAMP 466 pathway (Paavola, Sidik et al., 2014, Petersen et al., 2015). Our results showed that $\operatorname{csp}^{-/-}$ 467 larvae presented a significant decrease in Laminin expression in the PLLn and forcing 468 Laminin2 expression within the vicinity of the nerve was sufficient to activate the myelination 469 program in Schwann cells, drive radial sorting and re-establish axonal wrapping.

470 Based on all these findings, it was therefore interesting to assess the temporal setting and the 471 mechanism by which Schwann cell division triggers myelination. This study and others have 
472 shown that Schwann cells go through extensive cell proliferation prior to myelination at

473 different timepoints of their development: (i) during migration and (ii) during radial sorting

474 once they finished migrating in zebrafish (Lyons et al., 2005) and rodents (Stewart, Morgan et

475 al., 1993). To understand how timely division impact on Schwann cell differentiation, we

476 used the cell division inhibitor, aphidicolin, to temporally block cell division at these two

477 essential timepoints of intensive Schwann cell proliferation and analyzed its impact on

478 myelination. To our surprise, it was Schwann cell division during migration that dictated the

479 radial sorting and myelination events. In addition to characterizing how temporal control of

480 mitotic exit impacts myelination, our study also provided documentation of the existence of a

481 restricted window of time (around 8 hours) during which Schwann cells have to divide while

482 migrating in order to initiate radial sorting and myelination in vivo. Several studies have

483 pointed to a role for Laminin in controlling Schwann cell proliferation but this is the first

484 study that implicates Schwann cell division, particularly during migration, in Laminin

485 expression and subsequent myelination. The temporal control of this particular division is

486 therefore an essential step towards initiating the myelination program through Laminin/cAMP

487 pathway, a role that stretches beyond simply increasing the pool of Schwann cells required to

488 continuously engulf the nerve as it grows.

489 To come back to the question of numbers, is it important to generate enough Schwann cells to

490 myelinate? Our findings reveal that the myelination defects observed in $c s p^{-/}$and aphidicolin-

491 treated embryos do not ensue from reducing Schwann cells numbers per se, since Laminin

492 overexpression can fully rescue the percentage of myelinated axons within the PLLn even if

493 Schwann cell numbers remain significantly reduced. It would be interesting to know in the

494 future to what extent we can reduce the number of Schwann cells before they fully stretch

495 along the axons and whether they would still be able to myelinate in presence of Laminin 496 under acute mechanical strain. 
497 Finally, we show that Schwann cells are a major source of Laminin within peripheral nerves

498 in zebrafish. Our clonal analysis shows that forcing Laminin expression autonomously within

499 Schwann cells is enough to secrete Laminin in the extracellular space and restore normal Mbp

500 expression within the vicinity of these cells in $c s p^{-/-}$and aphidicolin treated embryos.

501 In summary, our work provides evidence of a novel ON/OFF mechanism that links early

502 temporal control of Schwann cell division during migration to radial sorting and axonal 503 wrapping via Laminin/cAMP pathway in vivo.

504

505 Materials and Methods

506 Embryo care

507 Embryos were staged and cared for according to standard protocols

508 (https://zfin.org/zf info/zfbook/cont.html). $T g(f o x d 3: g f p)$ stable transgenic line, that labels

509 SCs was used in this study (Gilmour et al., 2002). $\operatorname{Tg}(\operatorname{sox} 10: G a l 4 V P 16)^{e l 159}$ was kindly

510 provided by Gage Crump. $C s p^{+/}$embryos $\left(s t i l^{c z 65}\right.$ ) were purchased from ZIRC. All animal

511 experiments were conducted with approved protocols at Inserm by DDPP Val de Marne,

512 France under license number F 94-043-013.

513

514 Plasmid constructs

515 pTol2-Sox10:Sil-P2A-mCherry: The sil-P2A-mCherry cassette allowing simultaneous

516 expression of sil and membrane-localized mCherry separated by the self-cleaving P2A

517 peptide was generated by PCR amplification.

518 The 5'-CGATTCACTAGTATGAACCGTGTACAAGTGGATTTTAAAGG-3' forward and 5'-GAAGTTCGTGGCTCCGGATCCAAAGAGCTTGGGGAGCTGCCGTAACC

$5203^{\prime}$ reverse primers were used onto the pDNR-lib-STIL cDNA bought from addgene and the $5^{\prime}$ 521 GGTTACGGCAGCTCCCCAAGCTCTTTGGATCCGGAGCCACGAACTTC-3' forward 
522 and 5'-CTATGACCATGATTACGCCAAG-3' reverse primers onto the pCS2-mCherry-

523 CAAX plasmid.

524 The resulting PCR fragment was digested by SpeI and NotI before sub-cloning into the 525 4725Sox10-cre vector (a gift from Robert Kelsh) to obtain the pSox10:sil-P2A-mCherry 526 plasmid.

527 p5UAS: lama2-mcherry-T2A-EGFPcaax: The pT2i5uasbiH2bChe-GFP (a gift from Michel 528 Volovitch) was used to amplify the 5 UAS sequence using 529 5'GTGGGCCCTGCGTCTAGAGTC3' forward and 530 5' CTCACCATATGGGCGACCGGTGG3' reverse primers. Then, in order to 531 replace Actal promoter, the PCR product was subcloned into the pacta1:lama2-mcherry-T2A532 EGFPcaax vector (a gift from Peter Currie and Kelly Monk) digested by ApaI and NdeI 533 enzymes.

534

535

536

537

538

539

540

541

542 54320 pg per embryo along with 100 pg of Tol2 transposase mRNA. pUAS-lama 2 was injected at 54420 pg per embryo.

545

$546 \quad$ In situ hybridization

\section{Microinjections}

Mito:gfp (a gift from Dominik Paquet) and $h 2 b:: g f p$ (a gift from Jon Clarke) mRNAs were synthesized using SP6 mMessage mMachine System after linearization with Not1 and injected at 200 pg per embryo. pTol2:sox10-sil-2A-mcherry-Caax was injected at $10 \mathrm{pg}$ per embryo along with 50 pg of Tol2 transposase mRNA (a gift from David Lyons). Rac1V12 (constitutively active Rac1, kindly provided by Nicolas David) mRNA were synthesized using SP6 mMessage mMachine System after linearization with Not1 and injected at 2-10 pg per embryo. pactal-lama2 (kindly provided by Kelly Monk and Peter Currie) was injected at 
547 In situ hybridization was performed following standard protocols using krox20 and mbp

548 probes (Fontenas, De Santis et al., 2016). Embryos were raised in egg water with PTU

$549(0.003 \%)$ to avoid pigmentation and were fixed overnight in $4 \%$ paraformaldehyde at $52 \mathrm{hpf}$

550 and 3 dpf. Embryos were dehydrated the next day and kept in methanol at $-20^{\circ} \mathrm{C}$. Embryos

551 were then rehydrated and treated with proteinase $\mathrm{K}$ and incubated overnight with the

552 corresponding probe. Embryos were then washed and the staining was revealed using anti-

553 digoxigenin antibody.

554

555 Immunofluorescence

556 The following antibodies and dilutions were used: mouse anti-acetylated tubulin (Sigma;

557 1/500; T7451), mouse anti-HuC/HuD neuronal protein (Invitrogen; 1/500; REF A21271),

558 rabbit anti-laminin (Sigma, 1/200; L9393), mouse anti-phospho Histone 3 (Ser 10) (Millipore;

559 1/500; Cat \# 06-570), rabbit anti-myelin basic protein (Custom produced (Tingaud-Sequeira

560 Angèle , Anja Knoll-Gellida a et al., 2017)), gift from Patrick Babin, 1/500), mouse anti-

561 EGFP (Millipore; 1/500; REF MAB3580). Primary antibodies were detected with appropriate

562 secondary antibodies conjugated to either Alexa 488, Alexa 568 or Alexa 647 (Invitrogen) at

563 a 1:500 dilution. For immunostaining, embryos were fixed in 4\% paraformaldehyde 1X PBS

564 overnight at $4^{\circ} \mathrm{C}$, then washed with 1xPBS to be dehydrated in Methanol for at least 6 hours

565 at $-20^{\circ}$ C. Samples were then rehydrated, digested with proteinase K and blocked with $0.5 \%$

566 triton in PBS and 10\% sheep serum and then incubated with primary antibody overnight at

$5674{ }^{\circ} \mathrm{C}$ (diluted in $\mathrm{PBS}+2 \%$ sheep serum). Larvae were then washed with PBS for a few hours

568 and then incubated with secondary antibody in $0.5 \%$ triton in PBS and $2 \%$ sheep serum

569 overnight at $4{ }^{\circ} \mathrm{C}$. Stained larvae were then imaged with a Leica SP8 confocal microscope. For

570 Laminin and Mbp staining, embryos were fixed in 4\% PFA for $30 \mathrm{~min}$ and treated for $7 \mathrm{~min}$

571 with acetone at $-20^{\circ} \mathrm{C}$. Samples were then blocked with $0.5 \%$ triton in PBS and $10 \%$ sheep 
572 serum and then incubated with primary antibody overnight at $4^{\circ} \mathrm{C}$ (diluted in $\mathrm{PBS}+2 \%$ sheep

573 serum). Larvae were then washed with PBS for a few hours and then incubated with

574 secondary antibody in $0.5 \%$ triton in PBS and $2 \%$ sheep serum for 3 hours at RT. For

575 Laminin fluorescence intensity quantification, the same parameters (Excitation/emission, gain

576 for detectors, lasers intensity) were applied for images' acquisition in controls, $c s p^{-/}$and

577 aphidicolin treated embryos and fluorescence intensity was measured using image J

578 (Analyze/measure).

579

\section{Aphidicolin, forskolin and AG1478 treatment}

581 Embryos were incubated in fish water containing $150 \mu \mathrm{M}$ aphidicolin diluted in DMSO

582 between 45 and $54 \mathrm{hpf}$ or 45 and 72 hpf and with $100 \mu \mathrm{M}$ between 22 and 40 hpf, 22 and 30

583 hpf or 22 and 34 hpf. Controls were incubated in equivalent amount of DMSO (0.5 and

$5840.33 \%$ ) solution during the same periods. It took around 2 to $3 \mathrm{~h}$ for the aphidicolin to become

585 fully efficient following incubation.

586 Embryos were incubated in fish water containing $20 \mu \mathrm{M}$ forskolin diluted in DMSO between

58745 and 54 hpf. Controls were incubated in equivalent amount of DMSO solution (0.1\%)

588 during the same period.

589 Embryos were incubated in fish water containing $4 \mu \mathrm{M}$ AG1478 diluted in DMSO between

59024 and 48 hpf. Controls were incubated in equivalent amount of DMSO solution (0.1\%)

591 during the same period.

592

593 Acridine orange staining

594 Embryos were anesthetized with $0.03 \%$ tricaine and incubated in fish water containing $5 \mu \mathrm{M}$

595 acridine orange for 20 minutes in the dark. After wash, they were embedded in $1.5 \%$ low

596 melting point agarose, and imaged with a Leica SP8 confocal microscope. 


\section{$598 \quad$ Live imaging}

599 Embryos were anesthetized with $0.03 \%$ tricaine and embedded in $1.5 \%$ low melting point 600 agarose. For mito:GFP tracking experiments, PLLn was examined at $48 \mathrm{hpf}$ from a lateral

601 view. A series of 10 minutes time-lapses were recorded. Recordings were performed at $27^{\circ} \mathrm{C}$ 602 using a Leica SP8 confocal microscope. For $T g(f o x d 3: g f p)$, $T g(f o x d 3: g f p) / c s p^{-/-}$as well as 603 controls and $c s p^{-/}$injected with $h 2 b: g f p$, PLLg was examined at $28 \mathrm{hpf}$ and $48 \mathrm{hpf}$ and 604 recordings were acquired for up to $12 \mathrm{~h}$.

605

606 Transmission electron microscopy

607 At 3 and 4 dpf, embryos were fixed in a solution of $2 \%$ glutaraldehyde, $2 \%$ paraformaldehyde 608 and $0.1 \mathrm{M}$ sodium cacodylate $\mathrm{pH} 7.3$ overnight at $4^{\circ} \mathrm{C}$. This was followed by a post-fixation 609 step in cacodylate-buffered $1 \%$ osmium tetroxide $\left(\mathrm{OsO}_{4}\right.$, Serva) for $1 \mathrm{~h}$ at $4{ }^{\circ} \mathrm{C}$ and in $2 \%$

610 uranyl acetate for $1 \mathrm{~h}$ at room temperature. The tissue was then dehydrated and embedded in 611 epoxy resin. Sections were contrasted with saturated uranyl acetate solution and were examined with a 1010 electron microscope (JEOL) and a digital camera (Gatan).

\section{Statistical analysis}

615 Means and standard deviations were calculated with Graph Pad Prism 7. All data were first 616 tested for normal distribution using the ShapiroWilk normality test combined with D'Agostino

617 \& Pearson normality test. All experiments with only two groups and one dependent variable 618 were compared using an unpaired $t$-test with Welch's correction if they passed normality test; 619 if not, groups were compared with the nonparametric Mann-Whitney test. Statistically 620 significant differences were determined using one-way ANOVA for all experiments with 621 more than two groups but only one dependent variable. Error bars depict standard errors of 
622 the mean (SEM). ns, p >0.05; *, p $\leq 0.05 ; * *, \mathrm{p} \leq 0.01 ; * * *, \mathrm{p} \leq 0.001 ; * * * *, \mathrm{p} \leq 0.0001 . \mathrm{n}$

623 represents the number of embryos.

624

625 Acknowledgments

626 We would like to thank Peter Currie and Kelly Monk for the pactal-lama2 plasmid, Michel

627 Volovitch and Sophie Vriz for $p U A S$ construct and discussing cloning strategy, Robert Kelsh

628 for sox10 promoter, Gage Crump for Tg(sox10:Gal4VP16) $)^{\text {ell59 }}$ embryos, Patrick Babin for

629 providing Mbp antibody and Jon Clarke for his critical reading of the manuscript. This work

630 was funded by Inserm and University Paris-Saclay. Emilie Lesport is funded by "Institut

631 Professeur Baulieu”.

632

633 Figure legends

634

635 Figure 1. Schwann cells show a regular pattern of division during radial sorting

636 (A) Still images of time-lapse imaging in $T g(f o x d 3: g f p)$ control and $T g(f o x d 3: g f p) / c s p^{-/-}$ 637 embryos. Arrows indicate Schwann cells along the PLLn at different timepoints prior to and 638 after division. Scale bars $=25 \mu \mathrm{m}$.

639 (B) Quantification of the time required for control (20 cells, $\mathrm{n}=6$ embryos) and $\operatorname{csp}^{-/-}(20$

640 cells, $\mathrm{n}=5$ embryos) Schwann cells to successfully complete mitotic division. (****, $\mathrm{p} \leq$ 641 0.0001). $\mathrm{m}$ or min, minutes.

642

643 Figure 2. Sil is essential for radial sorting and myelination by Schwann cells

644 Schematic illustration of a zebrafish larvae. PLLn is shown in red. Dotted line represents the 645 anterior-posterior position of cross section analysis in TEM. PLLn, posterior lateral line 646 nerve. 
647 TEM of a cross section of the PLLn at $3 \mathrm{dpf}$ in control (A) and $c s p^{-/-}$embryo (B) and at $4 \mathrm{dpf}$ 648 in control (C) and $c s p^{-/-}$(D). Magenta asterisks highlight some large caliber myelinated axons 649 (some shown at higher magnification in A', scale bar $=0.2 \mu \mathrm{m}$ ) and blue asterisks show some 650 large caliber non-myelinated axons. Scale bars $=0.5 \mu \mathrm{m}$. SC, Schwann cell. (A') Example of 651 a 1:1 association between a Schwann cell and an axon, i.e. a radially sorted axon in control 652 embryo at 3 dpf. Scale bar $=0.5 \mu \mathrm{m}$. a, axon. Axons remained bundled in $\operatorname{csp}^{-/-}$whereby one 653 Schwann cell is associated with a bundle of axons, delimitated in white in B.

654 (E) Quantification of the number of myelinated axons per nerve at $3 \mathrm{dpf}$ in controls (9 nerves, $655 \mathrm{n}=5$ embryos) and $\operatorname{csp}^{--}(8$ nerves, $\mathrm{n}=6$ embryos) and at $4 \mathrm{dpf}$ in controls (average of $6568.3 \pm 0.57$ myelinated axons; 10 nerves, $\mathrm{n}=6$ embryos $)$ and $c s p^{-/}(0$ myelinated axon; 3 nerves, $657 \mathrm{n}=3$ embryos) $(* *, p=0.0035$ at $3 \mathrm{dpf} ; * *, p=0.005$ at $4 \mathrm{dpf})$.

658 (F) Quantification of the total number of axons per nerve at $3 \mathrm{dpf}$ in controls and $c s p^{-/}$and at $6594 \mathrm{dpf}$ in controls (54 \pm 3.16 axons) and $\operatorname{csp}^{-/}(23 \pm 1$ axons $)(* *, \mathrm{p}=0.003 ; * * * *, \mathrm{p} \leq 0.0001)$.

660 (G) Quantification of the percentage of myelinated axons relative to the total number of axons 661 per nerve at $3 \mathrm{dpf}$ in controls and $\operatorname{csp}^{-/}$and at $4 \mathrm{dpf}$ in controls $(15.44 \pm 0.87 \%)$ and $\operatorname{csp}^{-/}(0 \%)$ $662 \quad(* * * *, \mathrm{p} \leq 0.0001 ; * * * *, \mathrm{p} \leq 0.0001)$

663 (H) Quantification of the number of axons relative to their diameter at $3 \mathrm{dpf}$ in controls and $664 \operatorname{csp}^{-/-}(* *, p=0.0013 ; \mathrm{ns}, \mathrm{p}=0.14)$

665 (I) Quantification of the number of sorted axons per nerve at $3 \mathrm{dpf}$ in controls (average of $6667.00 \pm 0.52)$ and $\operatorname{csp}^{-/-}(0.37 \pm 0.26)(* * * *, \mathrm{p} \leq 0.0001)$

667 (J) Quantification of the percentage of sorted axons relative to the total number of axons at 3 $668 \mathrm{dpf}$ in controls $(12.97 \pm 1.21)$ and $c s p^{-/-}(1.95 \pm 1.55)(* *, \mathrm{p}=0.0019)$. 
671 TEM of a cross section of the PLLn at $3 \mathrm{dpf}$ in $c s p^{-/-}$(A) and $c s p^{-/}$embryos injected with

672 psox10-sil-P2A-mcherry (B). Magenta asterisks represent some large caliber myelinated 673 axons (some shown at higher magnification in B', B', , scale bars $=0.2 \mu \mathrm{m}$ ). Scale bars $=0.5$ $674 \mu \mathrm{m}$.

675 (C) Quantification of the percentage of myelinated axons relative to the total number of axons 676 in control (average of $10.46 \pm 1.14 \%, 9$ nerves, $\mathrm{n}=5$ embryos), $\operatorname{csp}^{-/}(0 \%, 8$ nerves, $\mathrm{n}=6$ 677 embryos) and $c s p^{-/}$injected with psox10-sil-P2A-mcherry (average of $8.64 \pm 1.20 \%, 3$ nerves, $678 \mathrm{n}=3$ embryos) $(* * * *, \mathrm{p} \leq 0.0001 ; \mathrm{ns}, \mathrm{p}=0.4871)$. Acetylated tubulin (Ac-tub) and Mbp 679 immuno-labeling in control (D-D"), $\operatorname{csp}^{-/-}$(E-E') and $c s p^{-/}+$psoxl0-sil-P2A-mcherry (F-G') 680 embryos at 3 dpf. Arrows indicate the PLLn in D and E, the myelin sheaths in D', mcherry+ 681 Schwann cells along the PLLn in F and G and the corresponding Mbp expression in F' and 682 G'. D', E', F', and G', are the corresponding merge images of D and D', E and E', F and F', $683 \mathrm{G}$ and G' respectively. Scale bars $=20 \mu \mathrm{m}$.

684

685 Figure 4. Schwann cells in $\operatorname{csp}^{-/-}$show delays in mitotic progression but exit mitosis with 686 no significant increase in apoptosis

687 (A) PH3 immuno-labeling in $T g(f o x d 3: g f p)$ and $T g(f o x d 3: g f p) / c s p^{-/}$at 48 hpf and 72 hpf. 688 Arrows indicate Schwann cells that are GFP and PH3 positives. Scale bar $=25 \mu \mathrm{m}$.

689 (B) Quantification of the number of Schwann cells within a defined region of the PLLn at 48 690 and $72 \mathrm{hpf}$ in control (average of $80.56 \pm 3.76$ cells at $48 \mathrm{hpf}, \mathrm{n}=9$ embryos; average of $69160 \pm 1.78$ cells at $72 \mathrm{hpf}, \mathrm{n}=11$ embryos) and $c s p^{-/-}$(average of $53.57 \pm 2.50$ at $48 \mathrm{hpf}, \mathrm{n}=9$ 692 embryos; average of $56.42 \pm 2.75$ cells at $72 \mathrm{hpf}, \mathrm{n}=12$ embryos $)(* * * *, \mathrm{p} \leq 0.0001 ; \mathrm{ns}, \mathrm{p}=$ $6930.2897)$.

694 (C) Quantification of the number of $\mathrm{PH}^{+} /$Schwann cells within a defined region of the PLLn 695 at 48 and $72 \mathrm{hpf}$ in control (average of 1.41 $\pm 0.37, \mathrm{n}=12$ embryos at $48 \mathrm{hpf}$; average of 
$6960.38 \pm 0.23, \mathrm{n}=13$ embryos at $72 \mathrm{hpf}$ ) and $c s p^{-/-}$(average of $10.56 \pm 1.34, \mathrm{n}=9$ embryos at $48 \mathrm{hpf}$;

697 average of $1.11 \pm 0.35, \mathrm{n}=9$ embryos at $72 \mathrm{hpf})(* * * *, \mathrm{p} \leq 0.0001 ; \mathrm{ns}, \mathrm{p}=0.064)$.

698 (D) Quantification of the ratio of $\mathrm{PH}^{+}$Schwann cells relative to the total number of Schwann

699 cells within a defined region of the PLLn at 48 and $72 \mathrm{hpf}$ in control (average of 1.68 \pm 0.48 ,

$700 \mathrm{n}=9$ embryos at $48 \mathrm{hpf}$; average of $0.75 \pm 0.41, \mathrm{n}=11$ embryos at $72 \mathrm{hpf}$ ) and $\operatorname{csp}^{-/-}$(average of

$70120.13 \pm 2.82, \mathrm{n}=9$ embryos at $48 \mathrm{hpf}$; average of $1.59 \pm 0.64, \mathrm{n}=12$ embryos at $72 \mathrm{hpf})(* * *, \mathrm{p}=$

$702 \quad 0.0002 ; \mathrm{ns}, \mathrm{p}=0.3636)$.

703 (E) Still images of time-lapse imaging in control (average of $16.67 \pm 1.22$ min, 6 nuclei, $n=3$

704 embryos) and $\operatorname{csp}^{-/}$(average of $98.67 \pm 4.55 \mathrm{~min}, 6$ nuclei, $\mathrm{n}=3$ embryos) embryos injected 705 with $h 2 b: g f p$. Arrows indicate Schwann cells nuclei from the beginning of $\mathrm{M}$ phase (time 0 ) 706 when mitotic rounding takes place until the two nuclei split. Scale bars $=10 \mu \mathrm{m}$. m, minutes.

707 (F) Acridine orange (AO) staining at $50 \mathrm{hpf}$ in control and $c s p^{-/}$embryos within a defined 708 region of the PLLn and spinal cord. Scale bar $=25 \mu \mathrm{m}$.

709 (G) Quantification of the number of AO positive cells in control (average of $0.18 \pm 0.08, \mathrm{n}=11$ 710 embryos) and $c s p^{-/-}$(average of $0.27 \pm 0.09, \mathrm{n}=11$ embryos) within a defined region of the 711 PLLn (ns, p= 0.72).

712 (H) Quantification of the number of AO positive cells in control (average of $0.66 \pm 0.33, n=6$ 713 embryos) and $c s p^{-/-}$(average of $47.83 \pm 2.05, \mathrm{n}=6$ embryos) within a defined region of the 714 spinal cord $(* * * *, \mathrm{p} \leq 0.0001)$.

715

716 Figure 5. Schwann cell division during radial sorting is not required per se for 717 myelination by Schwann cells

718 TEM of a cross section of the PLLn at $3 \mathrm{dpf}$ in control (A), embryo treated with aphidicolin 719 between 45 and 54 hpf (B) and embryo treated with aphidicolin between 45 and 72 hpf (C). 
720 Magenta asterisks represent some large caliber myelinated axons, (some shown at higher

721 magnification in B' and C', scale bars $=0.2 \mu \mathrm{m})$. SC, Schwann cell. Scale bars $=0.5 \mu \mathrm{m}$.

722 (D) Quantification of the number of myelinated axons per nerve at $3 \mathrm{dpf}$ in controls (average

723 of $5.7 \pm 0.56,9$ nerves, $n=6$ embryos), embryos treated with aphidicolin between 45 and 54

724 hpf (average of $2.11 \pm 0.31,5$ nerves, $n=5$ embryos), and embryos treated with aphidicolin

725 between 45 and 72 hpf (average of $2.00 \pm 0.32,9$ nerves, $\mathrm{n}=5$ embryos) $(* * * *, \mathrm{p} \leq 0.0001$; ns, $726 \mathrm{p}=0.9790)$

727 (E) Quantification of the total number of axons per nerve at $3 \mathrm{dpf}$ in controls (average of $72857 \pm 2.9$ ), embryos treated with aphidicolin between 45 and 54 hpf (average of 25.11 \pm 2.04 ) and 729 embryos treated with aphidicolin between 45 and 72 hpf (average of 28.00土1.98) (****, $730 \mathrm{p} \leq 0.0001 ; \mathrm{ns}, \mathrm{p}=0.6574)$.

731 (F) Quantification of the percentage of myelinated axons relative to the total number of axons 732 per nerve at $3 \mathrm{dpf}$ in controls (average of 10.5 \pm 1.2 ), embryos treated with aphidicolin between 73345 and 54 hpf (average of 8.76 \pm 1.42 ) and embryos treated with aphidicolin between 45 and

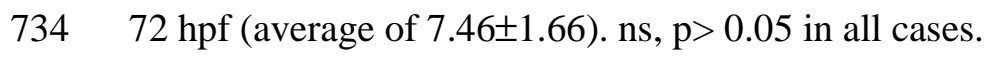

735 (G) Quantification of the percentage of axons according to their diameter relative to the total 736 number of axons per nerve at $3 \mathrm{dpf}$ in controls (average of 68.12 for 0-0.4 $\mu \mathrm{m}$; average of 73731.88 for $>0.4 \mu \mathrm{m}$ ) and aphidicolin treated embryos between 45 and $54 \mathrm{hpf}$ (average of 68.62 738 for 0-0.4 $\mu \mathrm{m}$; average of 31.38 for $>0.4 \mu \mathrm{m})$. $\mathrm{ns}, \mathrm{p}=0.9607$.

739 (H) Quantification of the percentage of axons according to their diameter relative to the total 740 number of axons per nerve at $3 \mathrm{dpf}$ in controls (average of 68.12 for $0-0.4 \mu \mathrm{m}$; average of 74131.88 for $>0.4 \mu \mathrm{m}$ ) and aphidicolin treated embryos between 45 and $72 \mathrm{hpf}$ (average of 70.76 742 for 0-0.4 $\mu \mathrm{m}$; average of 29.24 for $>0.4 \mu \mathrm{m})$. $\mathrm{ns}, \mathrm{p}=0.7545$. 
745 (A) Still images of time-lapse imaging in $T g(f o x d 3: g f p)$ control and $T g(f o x d 3: g f p) / c s p^{-/}$

746 embryos at around $30 \mathrm{hpf}$. Arrows indicate Schwann cells along the PLLn at different

747 timepoints prior to and after division. Scale bar $=20 \mu \mathrm{m}$.

748 (B) Quantification of the time required for control (11 cells, $\mathrm{n}=3$ embryos) and $\operatorname{csp}^{-/}(10$

749 cells, $n=3$ embryos) Schwann cells to successfully complete mitotic division during

750 migration. $(* * * *, \mathrm{p} \leq 0.0001)$. $\mathrm{m}$ or min, minutes.

751

752 Figure 7. Early Schwann cell division during migration is essential for myelination

753 (A) TEM of a cross section of the PLLn at $3 \mathrm{dpf}$ in control and embryo treated with

754 aphidicolin between 22 and 40 hpf. Magenta asterisks represent some large caliber myelinated

755 axons. SC, Schwann cell. Scale bars $=0.5 \mu \mathrm{m}$.

756 (B) Quantification of the number of myelinated axons per nerve at $3 \mathrm{dpf}$ in controls (average

757 of $5.63 \pm 0.45,11$ nerves, $n=7$ embryos) and embryos treated with aphidicolin between 22 and

$75840 \mathrm{hpf}($ average of $0.125 \pm 0.125,8$ nerves, $\mathrm{n}=6$ embryos) (****, $\mathrm{p} \leq 0.0001)$

759 (C) Quantification of the total number of axons per nerve at $3 \mathrm{dpf}$ in controls (average of

$76055.09 \pm 2.32$ ) and embryos treated with aphidicolin between 22 and 40 hpf (average of

$76120 \pm 3.04)(* * * *, p \leq 0.0001)$.

762 (D) Quantification of the percentage of myelinated axons relative to the total number of axons

763 per nerve at $3 \mathrm{dpf}$ in controls (average of 10.36 \pm 0.93 ) and embryos treated with aphidicolin

764 between 22 and 40 hpf (average of $0.46 \pm 0.46)(* * * *, p \leq 0.0001)$

765 (E) Quantification of the percentage of axons according to their diameter relative to the total

766 number of axons per nerve at $3 \mathrm{dpf}$ in controls (average of 68.12 for $0-0.4 \mu \mathrm{m}$; average of

76731.88 for $>0.4 \mu \mathrm{m}$ ) and aphidicolin treated embryos between 22 and $40 \mathrm{hpf}$ (average of 53.69

768 for $0-0.4 \mu \mathrm{m}$; average of 46.31 for $>0.4 \mu \mathrm{m})$. $n s, \mathrm{p}=0.2045$. 
769 (F) Quantification of the number of Schwann cells within a defined region of the PLLn at 52

770 hpf in control (average of $59.10 \pm 2.44$ cells, $\mathrm{n}=10$ embryos) and embryos treated with

771 aphidicolin between 22 and 40 hpf (average of $18 \pm 3.27$ cells, $\mathrm{n}=11$ embryos) $(* * * *, \mathrm{p} \leq$ $7720.0001)$

773 (G) Quantification of the number of $\mathrm{PH}^{+} /$Schwann cells within a defined region of the PLLn

774 at 52 hpf in control (average of $0.87 \pm 0.47, \mathrm{n}=8$ embryos) and embryos treated with

775 aphidicolin between 22 and 40 hpf (average of $0.18 \pm 0.12, n=11$ embryos) (ns, $\mathrm{p}=0.3265)$.

776 (H) Quantification of the ratio of $\mathrm{PH}^{+}$Schwann cells relative to the total number of Schwann

777 cells within a defined region of the PLLn at $52 \mathrm{hpf}$ in control (average of $2.54 \pm 0.95, \mathrm{n}=10$

778 embryos) and embryos treated with aphidicolin between 22 and $40 \mathrm{hpf}$ (average of 2.34 \pm 1.65 ,

$779 \mathrm{n}=11$ embryos $)(\mathrm{ns}, \mathrm{p}=0.3274)$.

780 (I) Still images of time-lapse imaging in $T g(f o x d 3: g f p)$ control and $T g(f o x d 3: g f p)$ treated with 781 aphidicolin between 22 and 40 hpf embryos at around 52 hpf. Arrows indicate Schwann cells

782 along the PLLn at different timepoints prior to and after division. Scale bars $=20 \mu \mathrm{m}$.

783 (J) Quantification of the time required for control (average of 8.70 $\pm 0.41 \mathrm{~min}, 20$ cells, $\mathrm{n}=5$

784 embryos) and embryos treated with aphidicolin between 22 and 40 hpf (average of $8.14 \pm 0.67$

785 min, 7 cells, $n=4$ embryos) Schwann cells to successfully complete mitotic division between

78648 and 60 hpf. (ns, p= 0.1796).

787

788 Figure 8. Sil is required to initiate myelin gene expression and axonal wrapping by 789 Schwann cells via cAMP dependent pathway

790 Lateral views of krox20 expression at $52 \mathrm{hpf}$ revealed by in situ hybridization along the PLLn

791 in control (A) showing a robust expression $(\mathrm{n}=29), \operatorname{csp}^{-/}$embryo (B) showing a sharp

792 decrease in krox20 expression $(\mathrm{n}=22)$ and in $\operatorname{csp}^{-/}$treated with forskolin $(\mathrm{FSK})(\mathrm{C})$ showing a 
793 robust expression similar to controls $(n=30)$. Arrows indicate Schwann cells expressing

794 krox20 along the PLLn.

795 Lateral views of $m b p$ expression at $3 \mathrm{dpf}$ revealed by in situ hybridization along the PLLn in

796 control (D) showing a robust expression $(n=31), c s p^{-/-}$embryo (E) showing a sharp decrease in

$797 m b p$ expression $(\mathrm{n}=24)$ and in $c s p^{-/-}$treated with forskolin $(\mathrm{F})$ showing a robust expression

798 similar to controls ( $\mathrm{n}=28$ ). Arrows indicate Schwann cells expressing $m b p$ along the PLLn.

799 Scale bar $=200 \mu \mathrm{m}$.

800 TEM of a cross section of the PLLn at $3 \mathrm{dpf}$ in control $(\mathrm{G}), \operatorname{csp}^{-/-}(\mathrm{H})$ and $c s p^{-/-}$treated with

801 forskolin between 45 and 54 hpf (I). Magenta asterisks represent some large caliber

802 myelinated axons. SC, Schwann cell. Scale bars $=0.5 \mu \mathrm{m}$.

803 (J) Quantification of the percentage of myelinated axons relative to the total number of axons

804 per nerve at $3 \mathrm{dpf}$ in controls (average of 10.6 \pm 1.17 ), $c s p^{-/-}$(average of 0 ) and $c s p^{-/-}$treated

805 with forskolin (average of $8.74 \pm 1.77$ ) (****, $\mathrm{p} \leq 0.0001 ; \mathrm{ns}, \mathrm{p}=0.4846 ; * * * *, \mathrm{p} \leq 0.0001$ ).

806 (K) TEM of a cross section of the PLLn at $3 \mathrm{dpf}$ in $c s p^{-/-}$embryo injected with a constitutive 807 active form of Rac1 (caracl). Scale bar $=0.5 \mu \mathrm{m}$.

808 (L) Quantification of the percentage of myelinated axons relative to the total number of axons 809 per nerve at $3 \mathrm{dpf}$ in controls (average of 10.5 \pm 1.13 ), $\operatorname{csp}^{-/}$(average of 0 ) and $c s p^{-/}$injected 810 with caracl (average of 0$)(* * * *, p \leq 0.0001, \mathrm{~ns}, \mathrm{p} \geq 0.999)$.

812 Figure 9. Laminin expression is significantly reduced in $c s p^{-/-}$and Laminin $\alpha 2$ over813 expression rescues radial sorting and myelination defects in $c s p^{-/-}$embryos without 814 increasing the number of Schwann cells

815 Laminin expression in control $(\mathrm{A}, \mathrm{n}=15)$ and $\operatorname{csp}^{--}(\mathrm{B}, \mathrm{n}=18)$ embryos at 48 hpf showing the 816 PLLn nerve (arrows). Scale bar $=20 \mu \mathrm{m}$. (C) Quantification of Laminin fluorescence 817 intensity along the PLLn in controls (average of 35.95 \pm 1.39 ) and $\operatorname{csp}^{-/}$(average of 
$81823.37 \pm 0.90)$ at $48 \mathrm{hpf}(* * * *, \mathrm{p} \leq 0.0001)$, a.u, arbitrary unit. (D) Lateral view of EGFP

819 expression in muscles surrounding the PLLn following pactal-lama2 injection. Scale bar $=$ $82020 \mu \mathrm{m}$. (E) Lateral view of mCherry tagged secreted Laminin in muscles and within the PLLn 821 (white arrows). TEM of a cross section of the PLLn at $3 \mathrm{dpf}$ in control $(\mathrm{F}), \operatorname{csp}^{-/}(\mathrm{G})$ and $\operatorname{csp}^{-/}$ $822+$ pactal-lama2 $(\mathrm{H})$ embryos. Magenta asterisks represent some large caliber myelinated 823 axons, some are shown at higher magnification in H'. Scale bars $=0.5 \mu \mathrm{m}$. (I) Quantification 824 of total number of axons per nerve at $3 \mathrm{dpf}$ in controls (average of 55.20 $\pm 2.56,10$ nerves, $\mathrm{n}=$ 8256 embryos), $\operatorname{csp}^{-/-}$(average of $29.56 \pm 2.55,9$ nerves, $\mathrm{n}=7$ embryos) and $\operatorname{csp}^{-/}+$pactal-lama2 826 (average of $34.78 \pm 1.84,9$ nerves, $\mathrm{n}=7$ embryos) (****, $\mathrm{p} \leq 0.0001 ; \mathrm{ns}, \mathrm{p}=0.1190$ ). (J) 827 Quantification of the percentage of myelinated axons relative to the total number of axons per 828 nerve at $3 \mathrm{dpf}$ in controls (average of 10.82 \pm 1.085$), \operatorname{csp}^{-/-}$(average of $0 \pm 0$ ) and $\operatorname{csp}^{-/}+$pactal829 lama2 (average of 8.28 \pm 0.77 ) (****, $\mathrm{p} \leq 0.0001 ; \mathrm{ns}, \mathrm{p}=0.075)$. (K) Quantification of the time 830 required for control (average of $9.66 \pm 0.39,12$ cells, $\mathrm{n}=4$ embryos), $\operatorname{csp}^{-/}$(average of $83186.80 \pm 4.77,10$ cells, $\mathrm{n}=4$ embryos) and $c s p^{-/}$injected with pactal-lama2 (average of $83288.60 \pm 4.31,10$ cells, $n=4$ embryos) Schwann cells to successfully complete mitotic division 833 during migration (****, $\mathrm{p} \leq 0.0001$; $\mathrm{ns}, \mathrm{p}=0.7828$ ). min, minutes. (L) Quantification of the 834 time required for control (average of $9.77 \pm 0.61,9$ cells, $\mathrm{n}=4$ embryos), $\operatorname{csp}^{-/}$(average of $83594.42 \pm 14.18,19$ cells, $\mathrm{n}=4$ embryos) and $c s p^{-/}$injected with pacta-lama2 (average of $836100.2 \pm 10.01,12$ cells, $n=4$ embryos) Schwann cells to successfully complete mitotic division 837 during radial sorting (****, $\mathrm{p} \leq 0.0001$; ns, $\mathrm{p}=0.1424)$. (M) Quantification of the number of 838 Schwann cells within a defined region of the PLLn at $48 \mathrm{hpf}$ in controls (average of $83977.45 \pm 2.05$ cells, $\mathrm{n}=20$ embryos), $\operatorname{csp}^{-/}$(average of $51.60 \pm 1.40, \mathrm{n}=20$ embryos) and $c s p^{-/-}$ 840 injected with pactal-lama2 (average of $48.18 \pm 1.74$ cells, $\mathrm{n}=11$ embryos), $(* * * *, \mathrm{p} \leq 0.0001$; $841 \mathrm{~ns}, \mathrm{p}=0.1402)$. 
843 Figure 10. Laminin $\alpha 2$ overexpression rescues defective myelination in embryos with

\section{4 delayed Schwann cell division during migration}

845 Laminin expression in a control embryo $(\mathrm{A}, \mathrm{n}=15)$ and aphidicolin treated embryo $(\mathrm{B}, \mathrm{n}=15)$

846 at $48 \mathrm{hpf}$ showing the PLLn nerve (arrows). Scale bar $=20 \mu \mathrm{m}$. (C) Quantification of Laminin

847 fluorescence intensity along the PLLn in controls (average of $36 \pm 1.4$ ) and aphidicolin treated 848 embryos (average of $26.80 \pm 0.92)$ at $48 \mathrm{hpf}(* * * *, \mathrm{p} \leq 0.0001)$, a.u, arbitrary unit. (D) Lateral

849 view of EGFP expression in muscles surrounding the PLLn following pactal-lama2

850 injection. Scale bar $=20 \mu \mathrm{m}$. (E) Lateral view of mCherry-tagged secreted Laminin in

851 muscles and within the PLLn (white arrows). TEM of a cross section of the PLLn at 3 dpf in 852 aphidicolin treated embryo (F) and aphidicolin treated embryo injected with pactal-lama2

853 (G). Magenta asterisks represent some large caliber myelinated axons, (some are shown at 854 higher magnification in $\mathrm{G}^{\prime}, \mathrm{G}^{\prime}$, , scale bars $=0.2 \mu \mathrm{m}$ ). Blue asterisks represent some large 855 caliber non myelinated axons. Scale bars $=0.5 \mu \mathrm{m}$. (H) Quantification of the total number of 856 axons per nerve at $3 \mathrm{dpf}$ in controls (average of 55.56 \pm 2.7 ), aphidicolin treated embryos 857 (average of $30.53 \pm 1.75$ ) and aphidicolin treated embryos + pactal-lama2 (average of $85826.00 \pm 2.32)(* * * *, p \leq 0.0001 ; \mathrm{ns}, \mathrm{p}=0.1401)$.

859 (I) Quantification of the percentage of myelinated axons relative to the total number of axons 860 per nerve at $3 \mathrm{dpf}$ in controls (average of $10.73 \pm 1.4,9$ nerves, $\mathrm{n}=6$ embryos), aphidicolin

861 treated embryos (average of $1.77 \pm 0.96,17$ nerves, $n=13$ embryos) and aphidicolin treated 862 embryos + pacta-lama2 (average of $15.53 \pm 3.61,8$ nerves, $\mathrm{n}=9$ embryos) (****, $\mathrm{p} \leq 0.0001$; **, $863 \mathrm{p}=0.0063 ; \mathrm{ns}, \mathrm{p}=0.2166)$. 


\section{Figure 11. Laminin expression is significantly reduced in AG1478 treated embryos and}

866 Laminin $\alpha 2$ over-expression within Schwann cells rescues Mbp expression defects in $\operatorname{csp}^{-}$

$86{ }^{/-}$and aphidicolin treated embryos

868 Laminin immuno-staining in foxd3:gfp (A-A', $\mathrm{n}=6)$ and foxd3:gfp embryos treated with

869 AG1478 (B-B', n=8) at 48 hpf. Arrows indicate GFP+ Schwann cells in A and Laminin

870 expression along the PLLn in A'. Scale bar $=20 \mu \mathrm{m}$. A'" and B' are the merge images of A

871 and $\mathrm{A}^{\prime}$ and of B and B' respectively. (C) Quantification of Laminin fluorescence intensity

872 along the PLLn in foxd3:gfp (average of 33.63 1 1.52) and foxd3:gfp/AG1478 treated embryos

873 (average of $21.67 \pm 1.44)(* *, p=0.0013)$, a.u, arbitrary unit. (D,E) Lateral views of EGFP

874 expression in Schwann cells of the PLLn following pUAS-lama2 injection in

875 sox10:Gal4VP16. Scale bars $=20 \mu \mathrm{m}$. (D',E') Lateral views of mCherry-tagged secreted

876 Laminin in Schwann cells and within the PLLn. (D',E'”) merge of D and D' and of E and E'

877 respectively. mCherry tagged secreted Laminin is highlighted in E', at higher magnification;

878 white arrows in D" and E", indicate extracellular Laminin within the PLLn and white

879 arrowheads in E' and E', indicate mCherry tagged Laminin within Schwann cells. (F)

880 Lateral view of Mbp immuno-labeling in control embryo at $3 \mathrm{dpf}$. Scale bar $=50 \mu \mathrm{m}$. $(\mathrm{G}$,

881 control, $n=24$ ) Lateral view showing the absence of EGFP expression in Schwann cells of the

882 PLLn that correlates with a significant decrease in Mbp immuno-labeling (G') following

883 pUAS-lama2 injection but with no EGFP/mCherry expression in $\operatorname{csp}^{-/} /$sox 10 :Gal4VP16.

884 Scale bar $=50 \mu \mathrm{m}$. (G' ') merge of $\mathrm{G}$ and $\mathrm{G}^{\prime}$. (H, $\left.\mathrm{n}=8\right)$ Lateral view showing EGFP expression

885 in Schwann cells of the PLLn that correlates with a normal Mbp immuno-labeling (H')

886 following pUAS-lama2 injection with positive clones of EGFP/mCherry in $\operatorname{csp}^{-/-}$

887 /sox10:Gal4VP16. Scale bar $=20 \mu \mathrm{m}$. (H') merge of $\mathrm{H}$ and H'. (I, control, $\mathrm{n}=26)$ Lateral

888 view showing the absence of EGFP expression in Schwann cells of the PLLn that correlates

889 with a significant decrease in Mbp immuno-labeling (I') following $p U A S$-lama2 injection but 
890 with no EGFP/mCherry expression in sox10:Gal4VP16 treated with aphidicolin between 22

891 and 34 hpf. Scale bar $=50 \mu \mathrm{m}$. (I') ) merge of I and I'. (J, n=9) Lateral view showing EGFP

892 expression in Schwann cells of the PLLn that correlates with a normal Mbp immuno-labeling

893 (J') following pUAS-lama2 injection with positive clones of EGFP/mCherry in 894 sox10:Gal4VP16 treated with aphidicolin between 22 and 34 hpf. Scale bar $=20 \mu \mathrm{m}$. (J') 895 merge of J and J'.

896

897 Supplemental information

898 Figure S1. Timeline of Schwann cell behavior and myelination in zebrafish. Schwann

899 cells migrate and divide along growing axons between $24 \mathrm{hpf}$ and $48 \mathrm{hpf}$. They start to 900 radially sort axons of the PLLn at around $48 \mathrm{hpf}$ and divide intensively. Myelin sheath is 901 analyzed starting from $3 \mathrm{dpf}$ (or $72 \mathrm{hpf}$ ). hpf, hours post fertilization; dpf, days post 902 fertilization; PLLn, posterior lateral line nerve.

903

904 Figure S2. Sil is not required for axonal growth nor for mitochondrial axonal transport 905 along the PLLn but regulates the number of neurons within the PLLg

906 (A) Acetylated tubulin expression in a control embryo $(\mathrm{n}=12)$ and $\operatorname{csp}^{-/-}$embryo $(\mathrm{n}=13)$ at 48

907 hpf showing the PLLn nerve (arrows). Lateral views of a control $(\mathrm{n}=16)$ and $c s p^{-/-}$embryo $908(\mathrm{n}=11)$ at $48 \mathrm{hpf}$ showing PLLn GFP-expressing Schwann cells (arrows). Scale bars $=50 \mu \mathrm{m}$.

909 (B) Still images from time-lapse imaging in control and $c s p^{-/}$embryos injected with mito:gfp.

910 Arrows point to the same mitochondria followed through time in control and $c s p^{-/}$. Scale bar $911=5 \mu \mathrm{m} . \mathrm{s}$, seconds.

912 (C) Quantification of the average speed of mitochondria along the PLLn at $50 \mathrm{hpf}$ in controls

913 (302 mitochondria, $\mathrm{n}=8$ embryos) and $c s p^{-/}$embryos (93 mitochondria, $\mathrm{n}=6$ embryos) (ns, $914 \mathrm{p}=0.6976)$. 
915 (D) HuC immuno-labeling of the PLLg at 48 and $72 \mathrm{hpf}$ in control and $c s p^{-/}$embryos. Scale 916 bar $=5 \mu \mathrm{m}$.

917 (E) Quantification of the number of neurons in the PLLg at $48 \mathrm{hpf}$ in control (average of $91854.58 \pm 5.99$ neurons, $\mathrm{n}=12$ ) and $\operatorname{csp}^{-/-}$(average of $31.71 \pm 5.31$ neurons, $\mathrm{n}=7$ ) embryos and at $91972 \mathrm{hpf}$ in control (average of $74.33 \pm 5.88$ neurons, $\mathrm{n}=12)$ and $\operatorname{csp} p^{-/-}(40.29 \pm 1.60$ neurons $\mathrm{n}=7)$ 920 embryos $(* * * *, \mathrm{p} \leq 0.0001 ; * * * *, \mathrm{p} \leq 0.0001)$.

921

922 Figure S3. Schwann cells have a limited window of time to divide during migration in 923 order to radially sort axons and myelinate

924 TEM of a cross section of the PLLn at $5 \mathrm{dpf}$ in control (A) and embryo treated with 925 aphidicolin between 22 and 34 hpf (B). Magenta asterisks highlight some large caliber 926 myelinated axons (some shown at higher magnification in $A^{\prime}$, scale bar $=0.2 \mu \mathrm{m}$ ) and blue 927 asterisks show some large caliber non-myelinated axons (some shown at higher magnification 928 in B', scale bar $=0.2 \mu \mathrm{m}$ ). Scale bars $=0.5 \mu \mathrm{m}$. (C) Quantification of the number of 929 myelinated axons per nerve at $5 \mathrm{dpf}$ in controls (average of $9 \pm 1.29,4$ nerves, $\mathrm{n}=4$ embryos) 930 and embryos treated with aphidicolin between 22 and $34 \mathrm{hpf}$ (average of 0,4 nerves, $\mathrm{n}=4$ 931 embryos) $(* *, p=0.0061)$.

932 (D) Quantification of the total number of axons per nerve at $5 \mathrm{dpf}$ in controls (average of $93349.75 \pm 3.32$ ) and embryos treated with aphidicolin between 22 and $34 \mathrm{hpf}$ (average of $93428.75 \pm 3.27)(* *, p=0.0041)$.

935 (E) Quantification of the percentage of myelinated axons relative to the total number of axons 936 per nerve at $5 \mathrm{dpf}$ in controls (average of 17.94 \pm 1.92 ) and embryos treated with aphidicolin 937 between 22 and $34 \mathrm{hpf}$ (average of 0$)(* *, p=0.0021)$.

938 (F) Quantification of the percentage of axons according to their diameter relative to the total 939 number of axons per nerve at $5 \mathrm{dpf}$ in controls (average of $66.66 \pm 5.26$ for $0-0.4 \mu \mathrm{m}$; average 
940 of $33.34 \pm 5.27$ for $>0.4 \mu \mathrm{m}$ ) and aphidicolin treated embryos between 22 and 34 hpf (average

941 of $54.34 \pm 6.7$ for $0-0.4 \mu \mathrm{m}$; average of $45.66 \pm 6.75$ for $>0.4 \mu \mathrm{m})$. ns, $\mathrm{p}=0.2209$.

942

943 Movie S1. Real-time imaging of Schwann cells in $\operatorname{Tg}(f \circ x d 3: g f p)$ at 48 hpf.

944 A 48 hpf embryo expressing GFP in Schwann cells; the control embryo was imaged every 4

945 minutes for several hours by confocal microscopy. Lateral view; anterior to the left and dorsal

946 to the top. This video represents four and a half hours of continuous real-time imaging.

947

948 Movie S2. Real-time imaging of Schwann cells in $\operatorname{Tg}(f \circ x d 3: g f p) / c s p^{-/-}$at 48 hpf.

949 A 48 hpf embryo expressing GFP in Schwann cells; the $c s p^{-/}$embryo was imaged every 4

950 minutes for several hours by confocal microscopy. Lateral view; anterior to the left and dorsal

951 to the top. This video represents four and a half hours of continuous real-time imaging.

952

953 Movie S3. Real-time imaging of mitochondria in a control PLLn at $48 \mathrm{hpf}$.

954 A 48 hpf control embryo expressing GFP in mitochondria after mito-gfp mRNA injection; the

955 embryo was imaged every 120 milliseconds for several minutes by confocal microscopy.

956 Lateral view; anterior to the left and dorsal to the top. This video represents 18 seconds of

957 real-time continuous imaging.

958

959 Movie S4. Real-time imaging of mitochondria in a $c s p^{-/-}$PLLn at 48 hpf.

960 A 48 hpf $c s p^{-/}$embryo expressing GFP in mitochondria after mito-gfp mRNA injection; the

961 embryo was imaged every 120 milliseconds for several minutes by confocal microscopy.

962 Lateral view; anterior to the left and dorsal to the top. This video represents 36 seconds of

963 continuous real-time imaging.

964 


\section{Movie S5. Real-time imaging of Schwann cell nuclei in control at 48 hpf.}

966 A 48 hpf control embryo expressing GFP in Schwann cell nuclei after $h 2 b$-gfp mRNA

967 injection; the embryo was imaged every 4 minutes for several hours by confocal microscopy.

968 Lateral view; anterior to the left and dorsal to the top. This video represents 40 minutes of

969 continuous real-time imaging.

970

971 Movie S6. Real-time imaging of Schwann cell nuclei in $c s p^{-/}$at 48 hpf.

972 A $48 \mathrm{hpf} c s p^{-/-}$embryo expressing GFP in Schwann cell nuclei after $h 2 b$ - $g f p$ mRNA injection;

973 the embryo was imaged every 4 minutes for several hours by confocal microscopy. Lateral

974 view; anterior to the left and dorsal to the top. This video represents 100 minutes of

975 continuous real-time imaging.

976

977 Movie S7. Real-time imaging of Schwann cells in $\mathrm{Tg}(f \circ x \mathrm{~d} 3: g f p)$ at $28 \mathrm{hpf}$

978 A 28 hpf embryo expressing GFP in Schwann cells; the control embryo was imaged every 4

979 minutes for several hours by confocal microscopy. Lateral view; anterior to the left and dorsal

980 to the top. This video represents two hours of continuous real-time imaging.

981

982 Movie S8. Real-time imaging of Schwann cells in $\operatorname{Tg}(f \circ \mathrm{xd}: \mathrm{gfp}) / \mathrm{csp}^{-/ /}$at $28 \mathrm{hpf}$.

983 A 28 hpf embryo expressing GFP in Schwann cells; the $\operatorname{csp} p^{-/-}$embryo was imaged every 4

984 minutes for several hours by confocal microscopy. Lateral view; anterior to the left and dorsal

985 to the top. This video represents four hours of continuous real-time imaging.

986

987 Movie S9. Real-time imaging of Schwann cells in $\operatorname{Tg}(f \circ x d 3: g f p)$ at 48 hpf. 
988 A 48 hpf embryo expressing GFP in Schwann cells; the control embryo was imaged every 3

989 minutes for several hours by confocal microscopy. Lateral view; anterior to the left and dorsal

990 to the top. This video represents three hours of continuous real-time imaging.

991

992 Movie S10. Real-time imaging of Schwann cells in $\operatorname{Tg}(f \circ x d 3: g f p)$ treated with aphidicolin

993 between 22 and 40 hpf at 48 hpf.

994 A 48 hpf embryo expressing GFP in Schwann cells; the aphidicolin treated embryo was

995 imaged every 3.5 minutes for several hours by confocal microscopy. Lateral view; anterior to

996 the left and dorsal to the top. This video represents six hours of continuous real-time imaging.

997

998 References

999

1000

1001

1002

1003

1004

1005

1006

1007

1008

1009

1010

1011

1012

1013

1014

1015

1016

1017

1018

1019

1020

1021

1022

1023
Aplan PD, Lombardi DP, Ginsberg AM, Cossman J, Bertness VL, Kirsch IR (1990) Disruption of the human SCL locus by "illegitimate" V-(D)-J recombinase activity. Science 250: 1426-9

Aplan PD, Lombardi DP, Kirsch IR (1991) Structural characterization of SIL, a gene frequently disrupted in T-cell acute lymphoblastic leukemia. Mol Cell Biol 11: 5462-9

Benninger $Y$, Thurnherr T, Pereira JA, Krause S, Wu X, Chrostek-Grashoff A, Herzog D, Nave KA, Franklin RJ, Meijer D, Brakebusch C, Suter U, Relvas JB (2007) Essential and distinct roles for cdc42 and rac1 in the regulation of Schwann cell biology during peripheral nervous system development. J Cell Biol 177: 1051-61

Boucanova F, Chrast R (2020) Metabolic Interaction Between Schwann Cells and Axons Under Physiological and Disease Conditions. Front Cell Neurosci 14: 148

Boueid MJ, Mikdache A, Lesport E, Degerny C, Tawk M (2020) Rho GTPases Signaling in Zebrafish Development and Disease. Cells 9

Bunge MB, Clark MB, Dean AC, Eldridge CF, Bunge RP (1990) Schwann cell function depends upon axonal signals and basal lamina components. Ann N Y Acad Sci 580: 281-7

Bunge MB, Williams AK, Wood PM (1982) Neuron-Schwann cell interaction in basal lamina formation. Dev Biol 92: 449-60

Campaner S, Kaldis P, Izraeli S, Kirsch IR (2005) Sil phosphorylation in a Pin1 binding domain affects the duration of the spindle checkpoint. Mol Cell Biol 25: 6660-72

Chen Z-L, Strickland S (2003) Laminin $\gamma 1$ is critical for Schwann cell differentiation, axon myelination, and regeneration in the peripheral nerve. Journal of Cell Biology 163: 889-899

Chernousov MA, Yu WM, Chen ZL, Carey DJ, Strickland S (2008) Regulation of Schwann cell function by the extracellular matrix. Glia 56: 1498-507

Colognato H, Tzvetanova ID (2011) Glia unglued: how signals from the extracellular matrix regulate the development of myelinating glia. Dev Neurobiol 71: 924-55 
1024 Court FA, Hewitt JE, Davies K, Patton BL, Uncini A, Wrabetz L, Feltri ML (2009) A laminin-2, 1025 dystroglycan, utrophin axis is required for compartmentalization and elongation of myelin 1026 segments. J Neurosci 29: 3908-19

1027 Cunningham RL, Herbert AL, Harty BL, Ackerman SD, Monk KR (2018) Mutations in dock1 1028 disrupt early Schwann cell development. Neural Dev 13: 17

1029 Eldridge CF, Bunge MB, Bunge RP (1989) Differentiation of Axon-Related Schwann Cells in 1030 V\&O:II. Control of Myelin Formation by Basal Lamina.

1031 Feltri ML, Graus Porta D, Previtali SC, Nodari A, Migliavacca B, Cassetti A, Littlewood-Evans A, 1032 Reichardt LF, Messing A, Quattrini A, Mueller U, Wrabetz L (2002) Conditional disruption of 1033 beta 1 integrin in Schwann cells impedes interactions with axons. J Cell Biol 156: 199-209

1034 Feltri ML, Poitelon Y, Previtali SC (2016) How Schwann Cells Sort Axons: New Concepts. 1035 Neuroscientist 22: 252-65

1036 Fontenas L, De Santis F, Di Donato V, Degerny C, Chambraud B, Del Bene F, Tawk M (2016)

1037 Neuronal Ndrg4 Is Essential for Nodes of Ranvier Organization in Zebrafish. PLoS Genet 12: 1038 e1006459

1039 Frob F, Wegner M (2019) The role of chromatin remodeling complexes in Schwann cell 1040 development. Glia

1041 Gilmour DT, Maischein HM, Nusslein-Volhard C (2002) Migration and function of a glial 1042 subtype in the vertebrate peripheral nervous system. Neuron 34: 577-88

1043 Glenn TD, Talbot WS (2013) Analysis of Gpr126 function defines distinct mechanisms 1044 controlling the initiation and maturation of myelin. Development 140: 3167-75

1045 Gomis-Coloma C, Velasco-Aviles S, Gomez-Sanchez JA, Casillas-Bajo A, Backs J, Cabedo H 1046 (2018) Class Ila histone deacetylases link CAMP signaling to the myelin transcriptional 1047 program of Schwann cells. J Cell Biol 217: 1249-1268

1048 Grava S, Schaerer F, Faty M, Philippsen P, Barral Y (2006) Asymmetric recruitment of dynein 1049 to spindle poles and microtubules promotes proper spindle orientation in yeast. Dev Cell 10: $1050 \quad 425-39$

1051 Grove M, Komiyama NH, Nave KA, Grant SG, Sherman DL, Brophy PJ (2007) FAK is required 1052 for axonal sorting by Schwann cells. J Cell Biol 176: 277-82

1053 Guo L, Moon C, Niehaus K, Zheng Y, Ratner N (2012) Rac1 controls Schwann cell myelination 1054 through cAMP and NF2/merlin. J Neurosci 32: 17251-61

1055 Hara M, Fukagawa T (2020) Dynamics of kinetochore structure and its regulations during 1056 mitotic progression. Cell Mol Life Sci

1057 Herbert AL, Monk KR (2017) Advances in myelinating glial cell development. Curr Opin 1058 Neurobiol 42: 53-60

1059 Jessen KR, Mirsky R (2005) The origin and development of glial cells in peripheral nerves. Nat 1060 Rev Neurosci 6: 671-82

1061 Kiyomitsu T, Cheeseman IM (2012) Chromosome- and spindle-pole-derived signals generate 1062 an intrinsic code for spindle position and orientation. Nat Cell Biol 14: 311-7

1063 Langworthy MM, Appel B (2012) Schwann cell myelination requires Dynein function. Neural 1064 Dev 7: 37

1065 Lara-Gonzalez P, Westhorpe FG, Taylor SS (2012) The spindle assembly checkpoint. Curr Biol 1066 22: R966-80

1067 Lu MS, Johnston CA (2013) Molecular pathways regulating mitotic spindle orientation in 1068 animal cells. Development 140: 1843-56 
1069 Lyons DA, Pogoda HM, Voas MG, Woods IG, Diamond B, Nix R, Arana N, Jacobs J, Talbot WS

1070 (2005) erbb3 and erbb2 are essential for schwann cell migration and myelination in 1071 zebrafish. Curr Biol 15: 513-24

1072 Ma Y, Kanakousaki K, Buttitta L (2015) How the cell cycle impacts chromatin architecture and 1073 influences cell fate. Front Genet 6: 19

1074 Michailov GV, Sereda MW, Brinkmann BG, Fischer TM, Haug B, Birchmeier C, Role L, Lai C, 1075 Schwab MH, Nave KA (2004) Axonal neuregulin-1 regulates myelin sheath thickness. Science 1076 304: 700-3

1077 Mikdache A, Fontenas L, Albadri S, Revenu C, Loisel-Duwattez J, Lesport E, Degerny C, Del 1078 Bene F, Tawk M (2020) Elmo1 function, linked to Rac1 activity, regulates peripheral neuronal 1079 numbers and myelination in zebrafish. Cell Mol Life Sci 77: 161-177

1080 Mogha A, Benesh AE, Patra C, Engel FB, Schoneberg T, Liebscher I, Monk KR (2013) Gpr126 1081 Functions in Schwann Cells to Control Differentiation and Myelination via G-Protein 1082 Activation. Journal of Neuroscience 33: 17976-17985

1083 Monk KR, Feltri ML, Taveggia C (2015) New insights on Schwann cell development. Glia 63: 1084 1376-93

1085 Monk KR, Naylor SG, Glenn TD, Mercurio S, Perlin JR, Dominguez C, Moens CB, Talbot WS 1086 (2009) A G protein-coupled receptor is essential for Schwann cells to initiate myelination. 1087 Science 325: 1402-5

1088 Nave KA, Salzer JL (2006) Axonal regulation of myelination by neuregulin 1. Curr Opin 1089 Neurobiol 16: 492-500

1090 Naveed M, Kazmi SK, Amin M, Asif Z, Islam U, Shahid K, Tehreem S (2018) Comprehensive 1091 review on the molecular genetics of autosomal recessive primary microcephaly (MCPH). In 1092 Genet Res (Camb),

1093 Newbern J, Birchmeier C (2010) Nrg1/ErbB signaling networks in Schwann cell development 1094 and myelination. Semin Cell Dev Biol 21: 922-8

1095 Nodari A, Previtali SC, Dati G, Occhi S, Court FA, Colombelli C, Zambroni D, Dina G, Del Carro 1096 U, Campbell KP, Quattrini A, Wrabetz L, Feltri ML (2008) Alpha6beta4 integrin and 1097 dystroglycan cooperate to stabilize the myelin sheath. J Neurosci 28: 6714-9

1098 Nodari A, Zambroni D, Quattrini A, Court FA, D'Urso A, Recchia A, Tybulewicz VL, Wrabetz L, 1099 Feltri ML (2007) Beta1 integrin activates Rac1 in Schwann cells to generate radial lamellae 1100 during axonal sorting and myelination. J Cell Biol 177: 1063-75

1101 Novorol C, Burkhardt J, Wood KJ, Iqbal A, Roque C, Coutts N, Almeida AD, He J, Wilkinson CJ, 1102 Harris WA (2013) Microcephaly models in the developing zebrafish retinal neuroepithelium 1103 point to an underlying defect in metaphase progression. Open Biol 3: 130065

1104 Paavola KJ, Sidik H, Zuchero JB, Eckart M, Talbot WS (2014) Type IV collagen is an activating 1105 ligand for the adhesion $G$ protein-coupled receptor GPR126. Sci Signal 7: ra76

1106 Pereira JA, Lebrun-Julien F, Suter U (2012) Molecular mechanisms regulating myelination in 1107 the peripheral nervous system. Trends Neurosci 35: 123-34

1108 Petersen SC, Luo R, Liebscher I, Giera S, Jeong SJ, Mogha A, Ghidinelli M, Feltri ML, 1109 Schoneberg T, Piao X, Monk KR (2015) The adhesion GPCR GPR126 has distinct, domain1110 dependent functions in Schwann cell development mediated by interaction with laminin1111 211. Neuron 85: 755-69

1112 Petry S (2016) Mechanisms of Mitotic Spindle Assembly. Annu Rev Biochem 85: 659-83

1113 Pfaff KL, Straub CT, Chiang K, Bear DM, Zhou Y, Zon LI (2007) The zebra fish cassiopeia 1114 mutant reveals that SIL is required for mitotic spindle organization. Mol Cell Biol 27: 5887-97 
1115 Raphael AR, Lyons DA, Talbot WS (2011) ErbB signaling has a role in radial sorting 1116 independent of Schwann cell number. Glia 59: 1047-55

1117 Raphael AR, Talbot WS (2011) New insights into signaling during myelination in zebrafish.

1118 Curr Top Dev Biol 97: 1-19

1119 Sherman DL, Brophy PJ (2005) Mechanisms of axon ensheathment and myelin growth. Nat 1120 Rev Neurosci 6: 683-90

1121 Silva PM, Reis RM, Bolanos-Garcia VM, Florindo C, Tavares AA, Bousbaa H (2014) Dynein-

1122 dependent transport of spindle assembly checkpoint proteins off kinetochores toward 1123 spindle poles. FEBS Lett 588: 3265-73

1124 Stewart HJS, Morgan L, Jessen KR, Mirsky R (1993) Changes in DNA Synthesis Rate in the 1125 Schwann Cell Lineage In Vivo Are Correlated With the Precursor - Schwann Cell Transition 1126 and Myelination.

1127 Sztal TE, Sonntag C, Hall TE, Currie PD (2012) Epistatic dissection of laminin-receptor 1128 interactions in dystrophic zebrafish muscle. Hum Mol Genet 21: 4718-31

1129 Tingaud-Sequeira Angèle DRb, Julie Lavie a, Guilaine Mathieu a, Magali Bordier a,C,, Anja 1130 Knoll-Gellida a PR, Isabelle Coupry a, Michèle André a, EvaMalmd, Claes Möller e,, Sten 1131 Andreasson d NDRf, Lisbeth Tranebjærg f, Michel Koenig g, Didier Lacombe a,c, Cyril Goizet 1132 a C, Patrick J. Babin a, ? (2017) Functional validation of ABHD12 mutations in the 1133 neurodegenerative disease PHARC. Neurobiology of Disease 36-51

1134 Tricaud N (2017) Myelinating Schwann Cell Polarity and Mechanically-Driven Myelin Sheath 1135 Elongation. Front Cell Neurosci 11: 414

1136 Woodhoo A, Sommer L (2008) Development of the Schwann cell lineage: from the neural 1137 crest to the myelinated nerve. Glia 56: 1481-90

1138 Yamada H, Denzer AJ, Hori H, Tanaka T, Anderson LVB, Fujita S, Fukuta-Ohi H, Shimizu T, 1139 Rueff MA, Matasumura K (1996) Dystroglycan Is a Dual Receptor for Agrin and Laminin-2 in 1140 Schwann Cell Membrane.

1141 Yang D, Bierman J, Tarumi YS, Zhong YP, Rangwala R, Proctor TM, Miyagoe-Suzuki Y, Takeda 1142 S, Miner JH, Sherman LS, Gold BG, Patton BL (2005) Coordinate control of axon 1143 defasciculation and myelination by laminin-2 and -8. J Cell Biol 168: 655-66

1144 Yu WM, Feltri ML, Wrabetz L, Strickland S, Chen ZL (2005) Schwann Cell-Specific Ablation of 1145 Laminin 1 Causes Apoptosis and Prevents Proliferation.

1146 Zaqout S, Morris-Rosendahl D, Kaindl AM (2017) Autosomal Recessive Primary Microcephaly 1147 (MCPH): An Update. Neuropediatrics 48: 135-142 
A

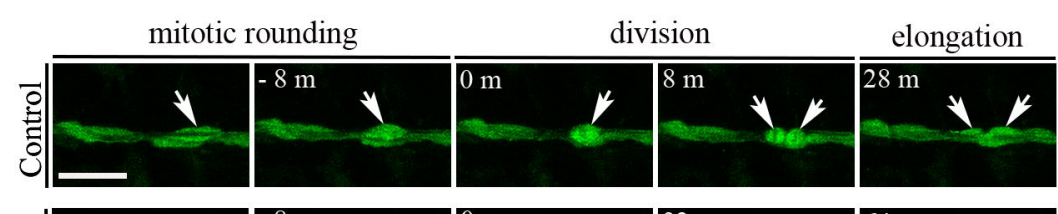

5

要

7-

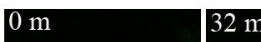

8

$64 \mathrm{~m}$

$88 \mathrm{~m}$

division
B

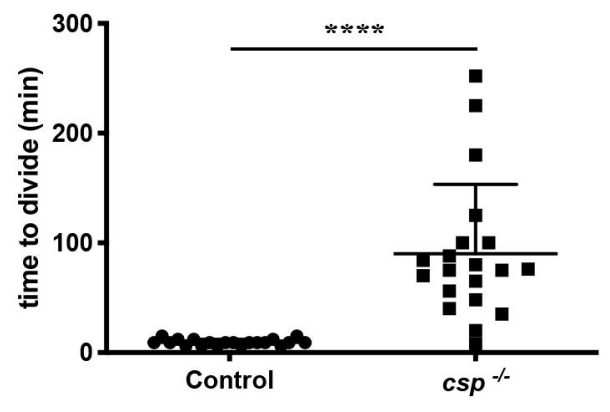



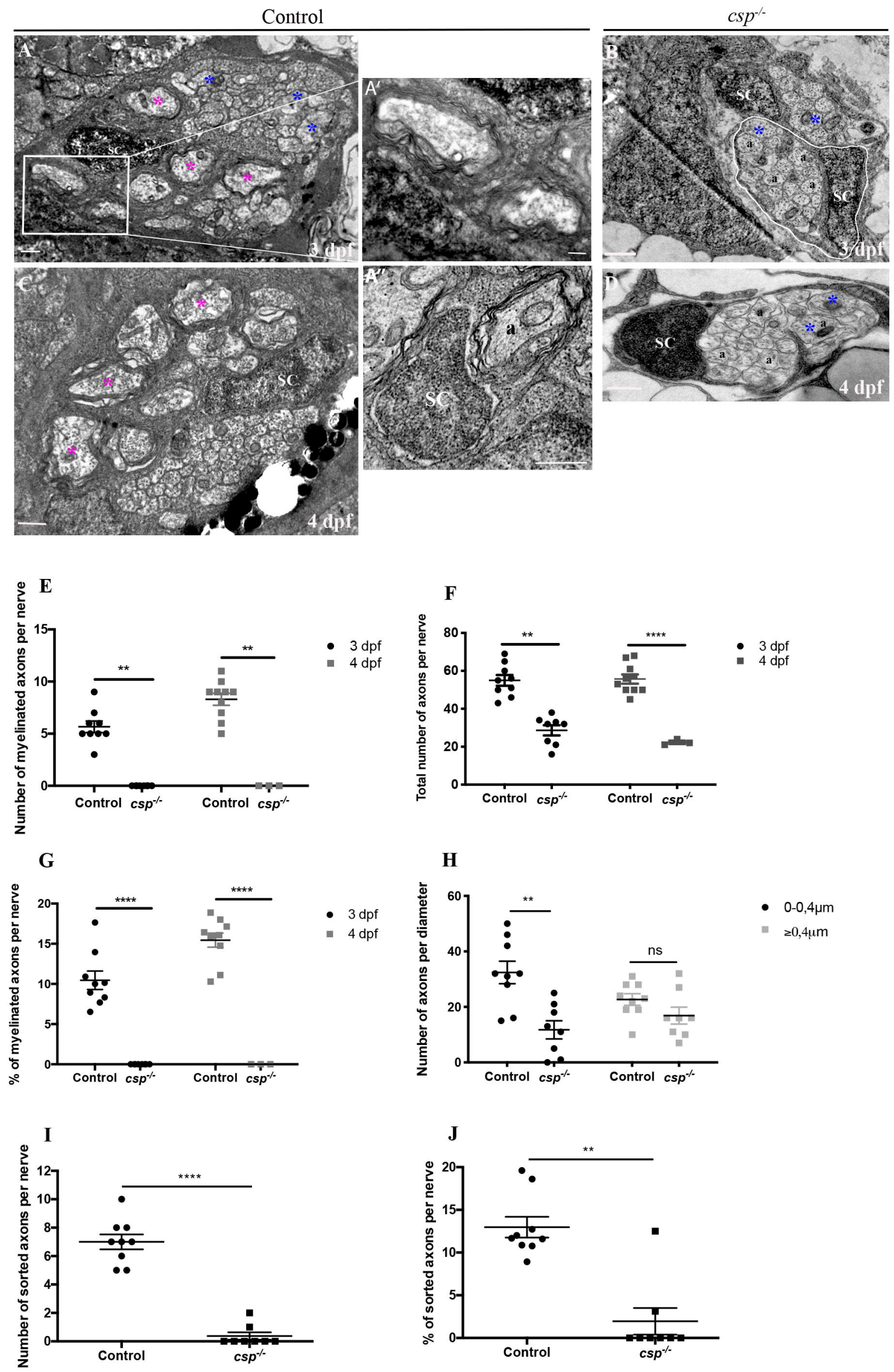

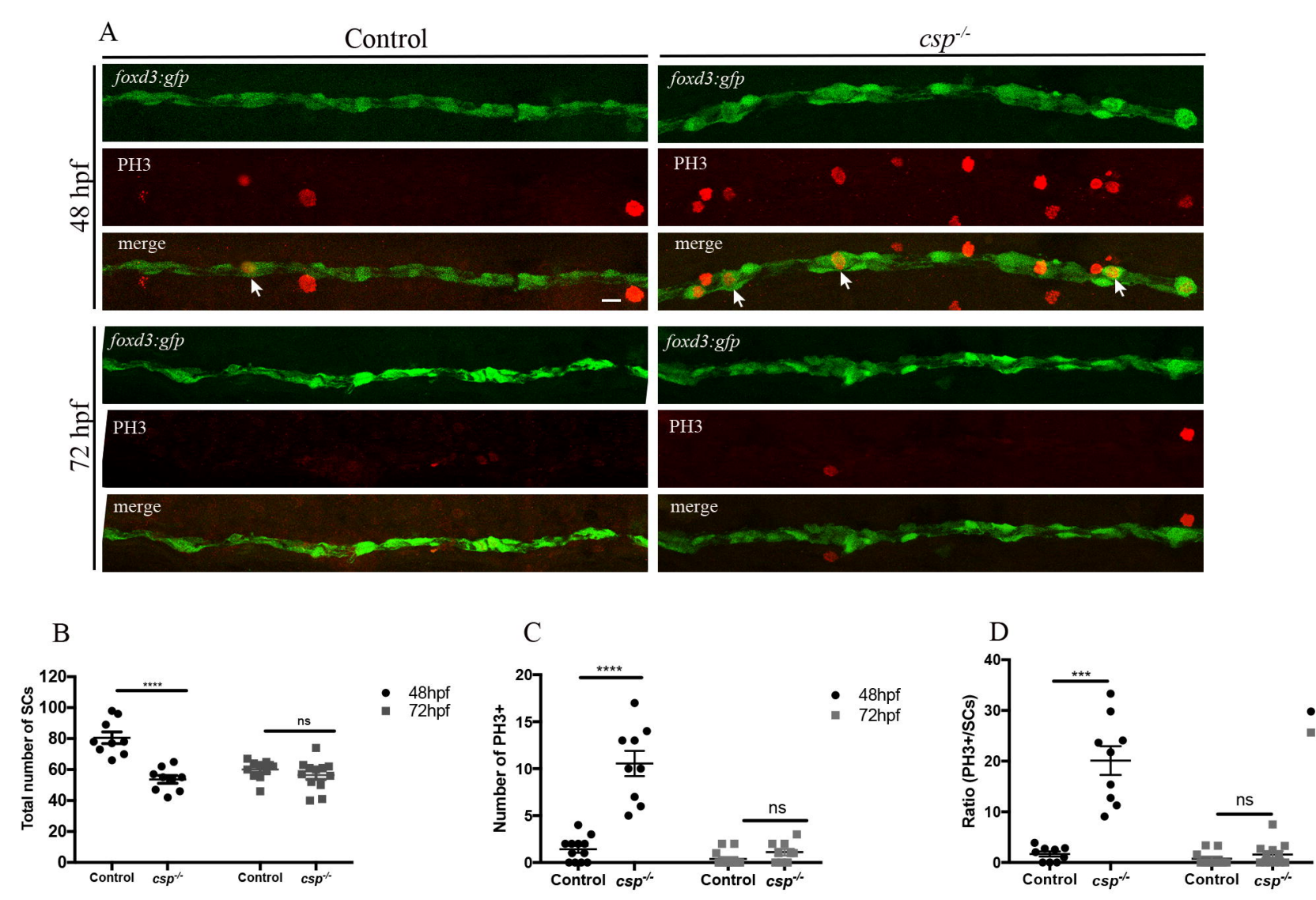

E
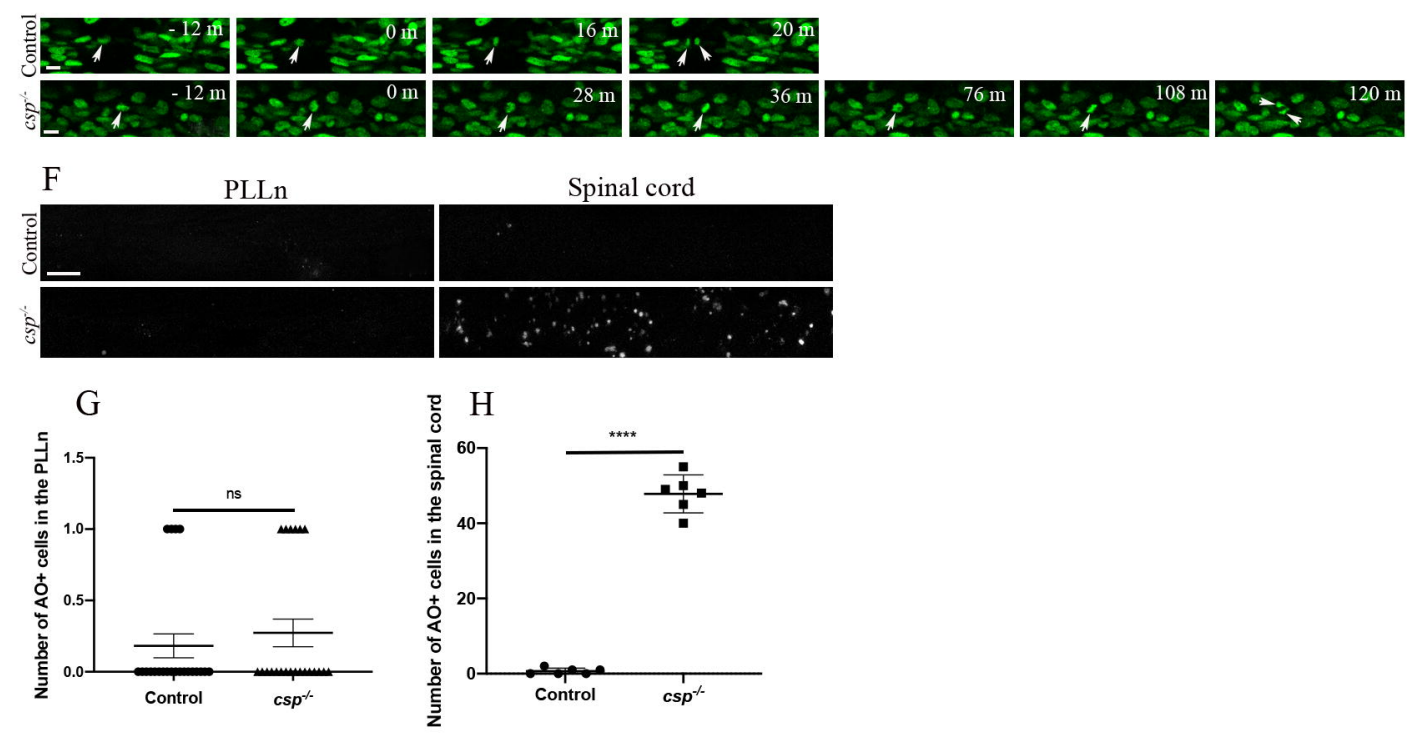

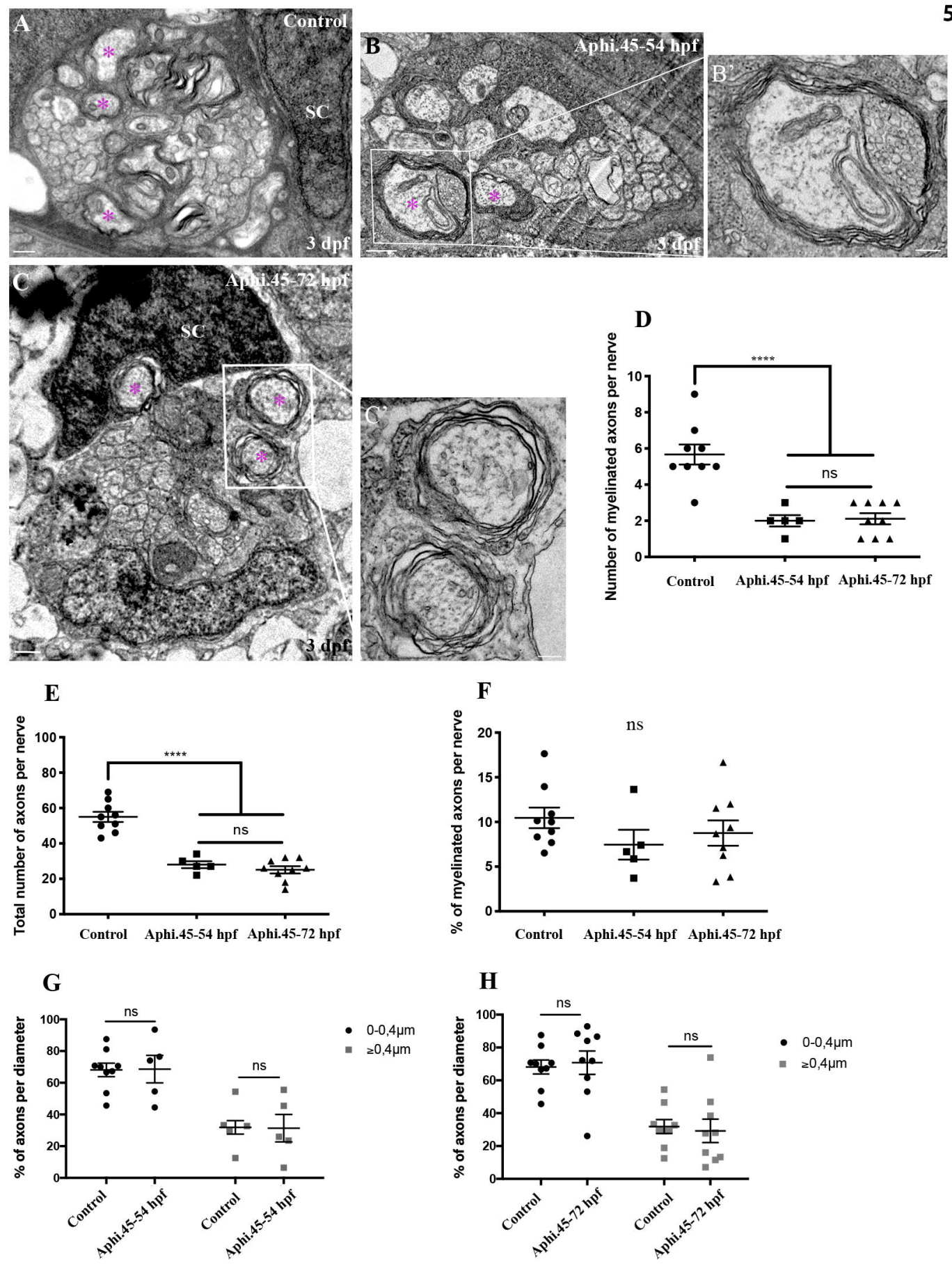
A

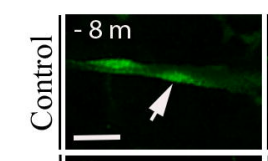

Fi
B

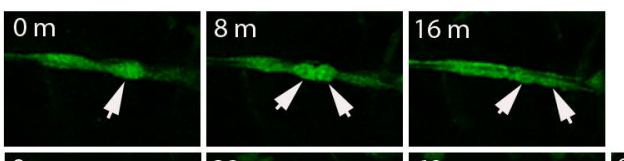

$28 \mathrm{~m} \quad 60 \mathrm{~m}$

.
$84 \mathrm{~m}$

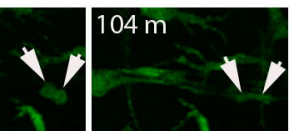

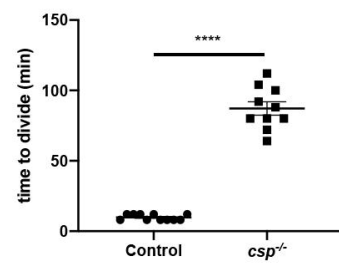




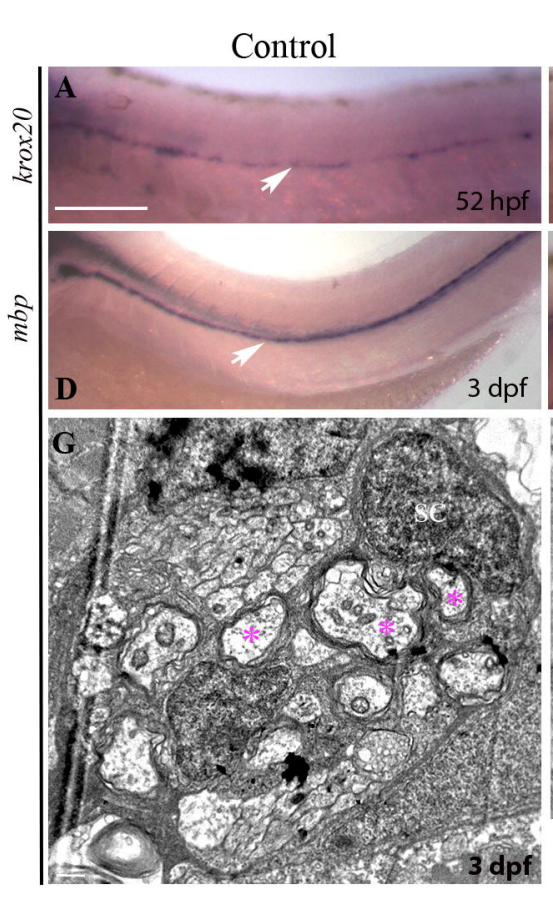

$c s p^{-\alpha}+\mathrm{FSK}$

8
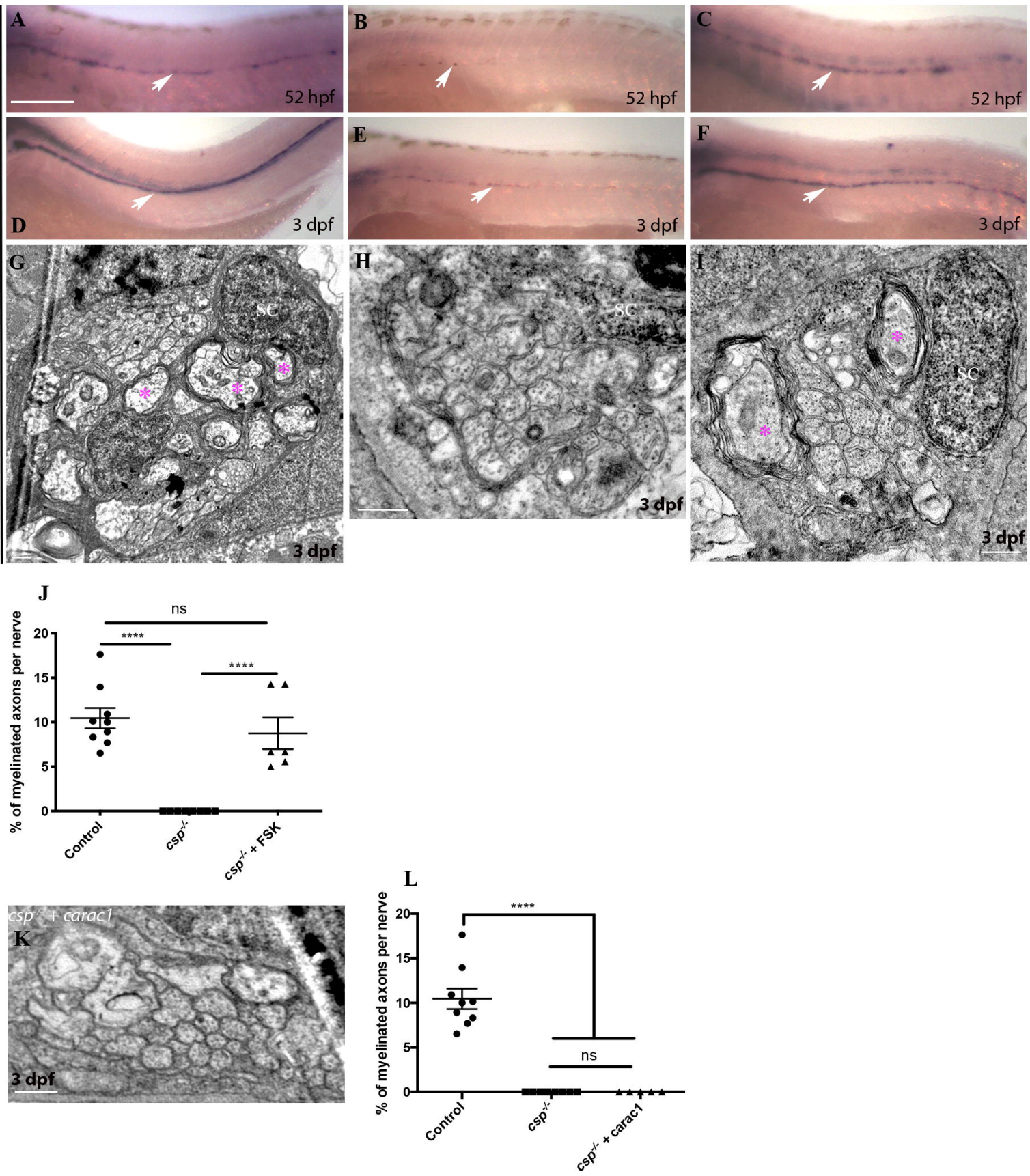

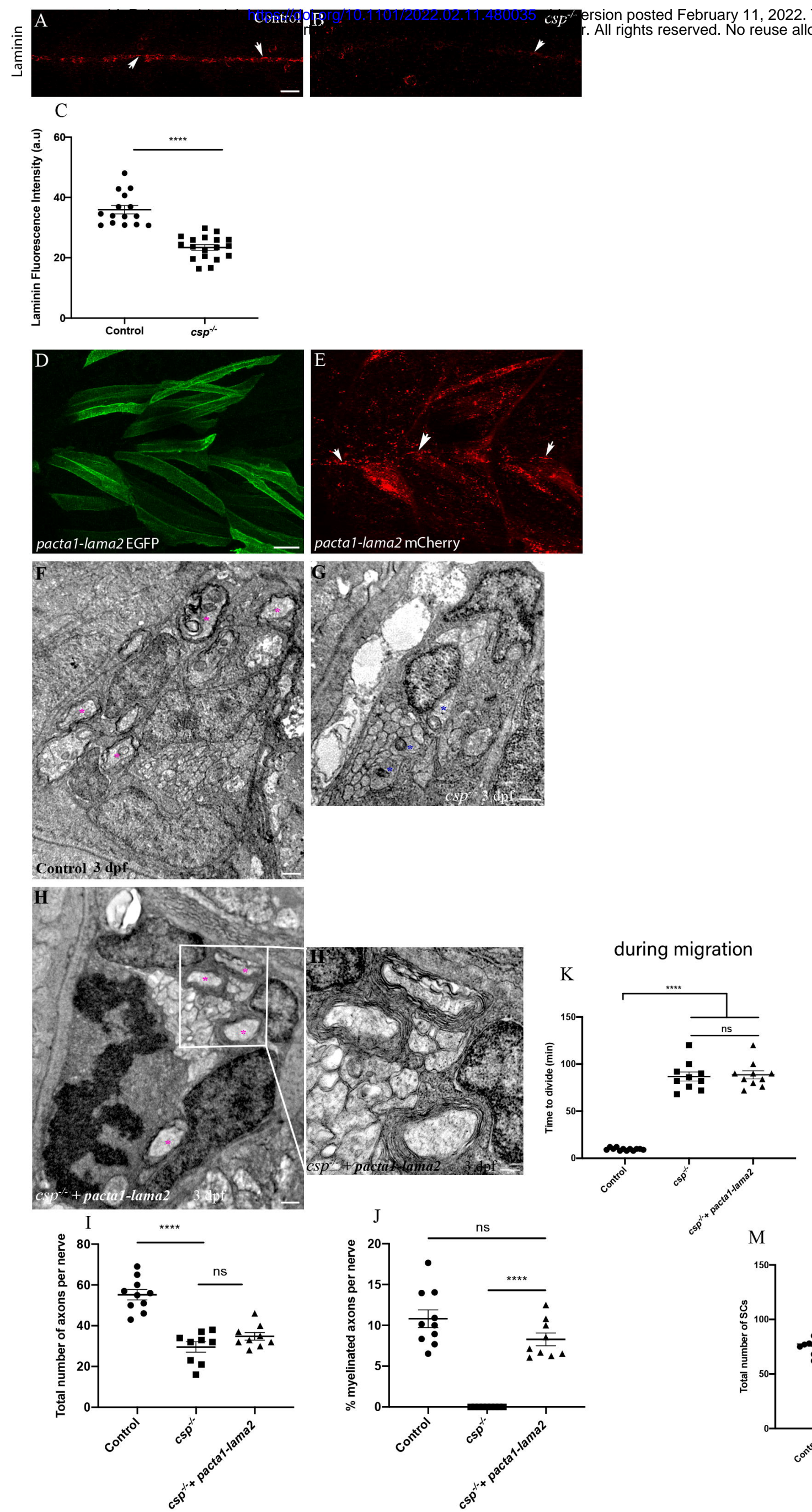

during radial sorting
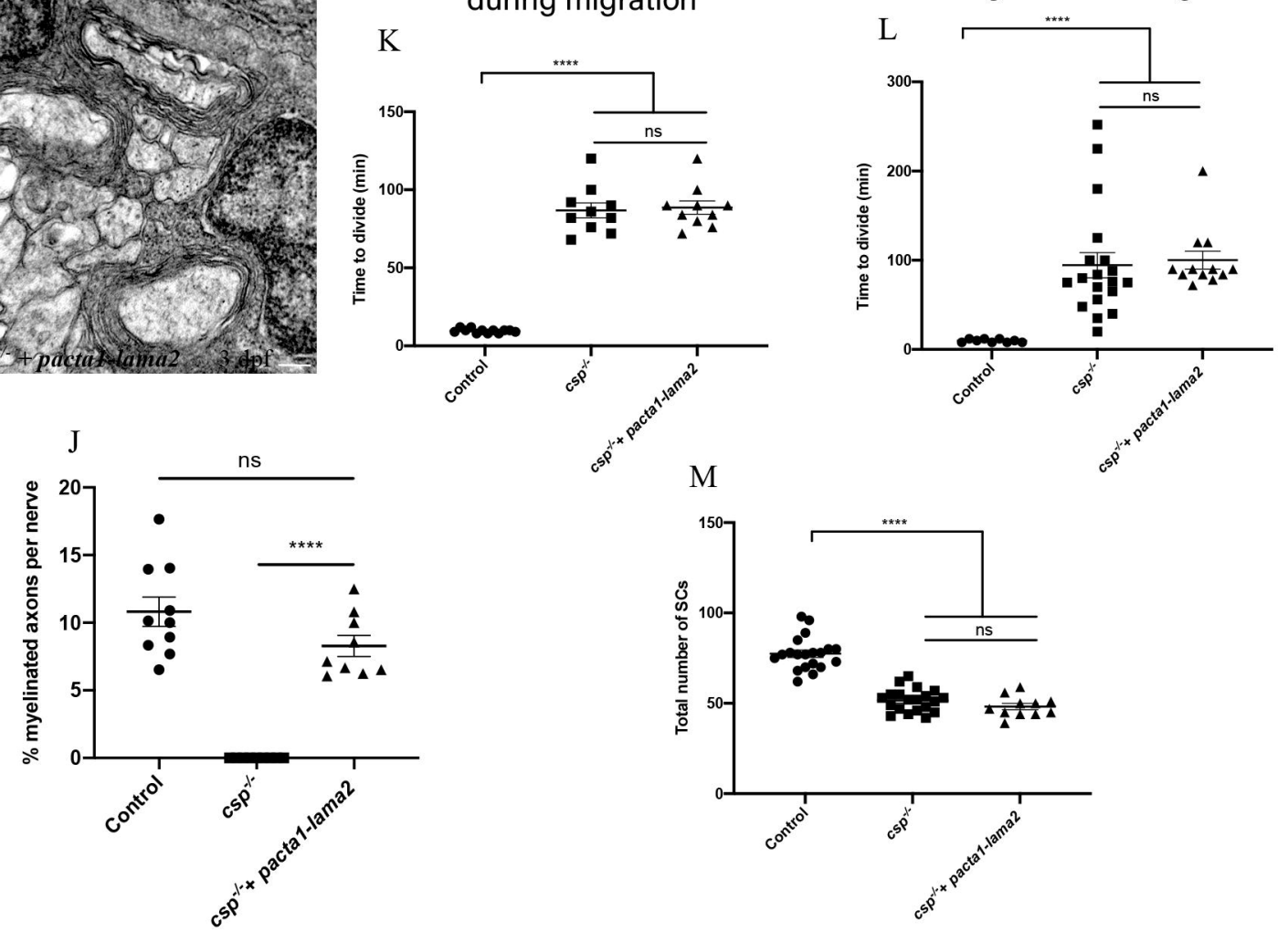

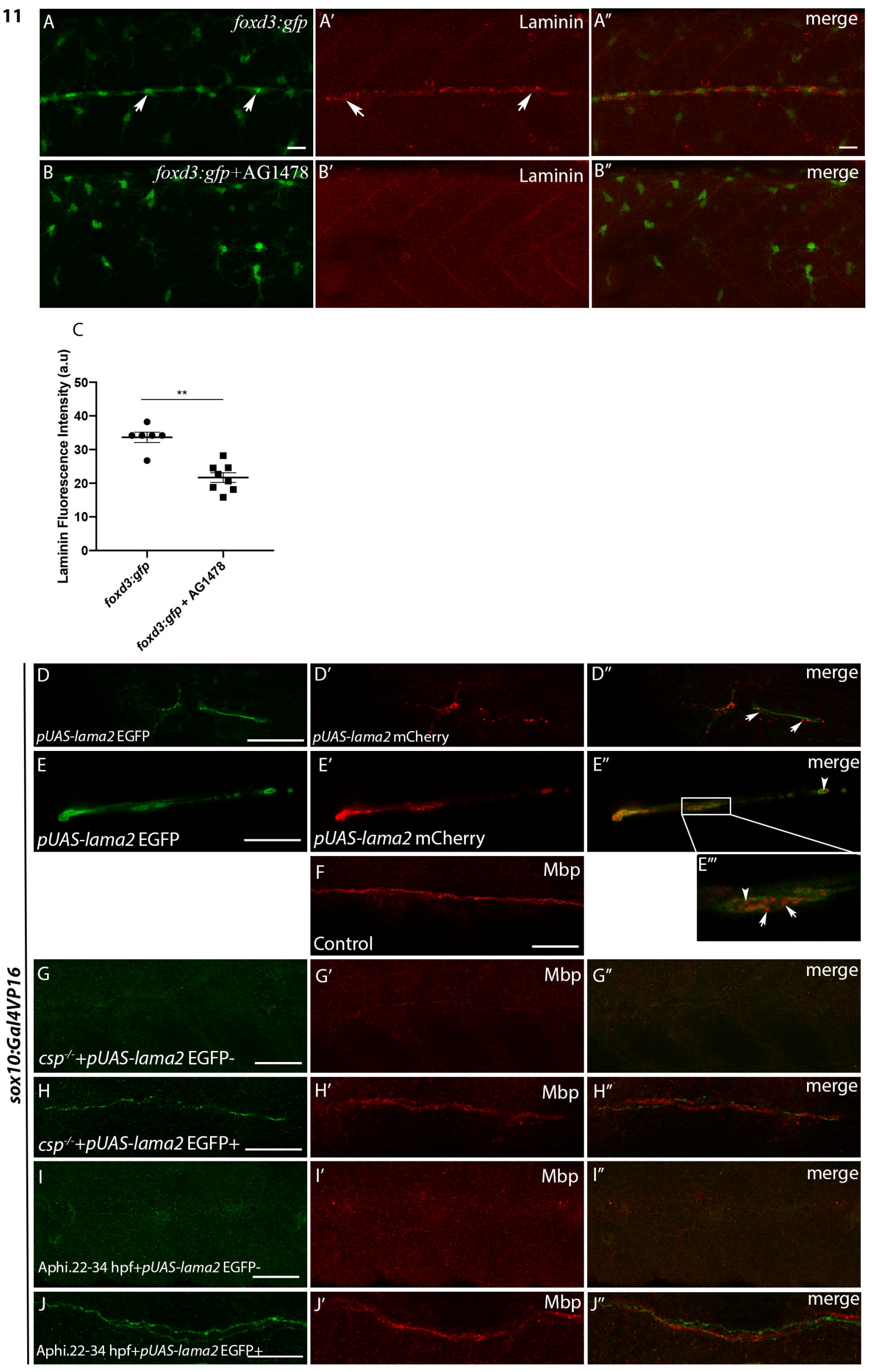